\title{
Mass Transfers Within Emulsions Studied by Differential Scanning Calorimetry (DSC) - Application to Composition Ripening and Solid Ripening
}

\author{
D. Clausse ${ }^{1}$, A. Drelich ${ }^{1}$ and B. Fouconnier ${ }^{2}$ \\ ${ }^{1}$ EA 4297 Transformations Intégrées de la Matière Renouvelable, \\ Université de Technologie de Compiègne; \\ ${ }^{2}$ Departamento de Ingeniería de Procesos y Hidráulica, \\ Universidad Autónoma Metropolitana; \\ ${ }^{1}$ France \\ ${ }^{2}$ México
}

\section{Introduction}

In this chapter mass transfer within simple, mixed and multiple emulsions will be considered. Simple emulsions are made of either water droplets dispersed within an oil phase $(\mathrm{W} / \mathrm{O})$ or oil droplets dispersed within an aqueous phase $(\mathrm{O} / \mathrm{W})$. Mixed emulsions are obtained by mixing gently to avoid coalescence, two simple emulsions the composition of the droplets being different. Finally, multiple or double emulsions are obtained by dispersing either a simple emulsion $(\mathrm{W} / \mathrm{O})$ in an aqueous phase to get what is referred as $\mathrm{W} / \mathrm{O} / \mathrm{W}$ emulsion or by dispersing a simple emulsion $(\mathrm{O} / \mathrm{W})$ in an oil phase to get an $\mathrm{O} / \mathrm{W} / \mathrm{O}$ emulsion.

These systems are known to be instable and their evolution towards bulk separated phases is the result of coalescence of the droplets due to different main mechanisms as Ostwald ripening, flotation, aggregation, sedimentation or creaming. This evolution can be considerably reduced by adding in their formulations either surfactants or/and particles. Thus, kinetic stability can be obtained. In that case other mechanisms can be studied, mechanisms that traduce an evolution of the systems as well but breakdown of the emulsions is not the result of the evolution understudy. It is this kind of evolution due to mass transfer that will be studied in this chapter. The bibliography will be done in each part dealing with the different kinds of emulsions considered.

First mass transfer in simple emulsions will be described. For these systems a not very well known mass transfer can be the result of the coexistence of still liquid droplets and yet solid ones at a temperature below the solid/liquid equilibrium temperature. This situation is the result of nucleation phenomena that create a delay for the formation of a solid germ that will induce the solidification of the droplets at different temperatures during the regular cooling of the emulsion. Another phenomenon leading to mass transfer in these systems is obtained by adding a material in the oil phase in a W/O emulsion, material that will diffuse and react 
chemically with the water of the dispersed droplets. Following this process, an example of hydrate formation will be described.

In mixed emulsions the transfer is due to the difference of composition between the two populations of droplets. The phase wherein they are dispersed plays the role of a liquid membrane and should this membrane be permeable to one of the material present in the droplets a mass transfer occurs as it can be observed in a direct osmosis device.

In multiple emulsions, the situation is very similar of the one observed in mixed emulsions, except that the phases involved in the mass transfer are the dispersed droplets in the globules (primary emulsion) and the continuous phase wherein the globules are dispersed. A difference in the composition between these two kinds of phases lead to a mass transfer, the material of the globules playing in that case the role of a liquid membrane.

Different techniques have been used to detect this kind of mass transfer in emulsions. They are based on the phenomena linked with the mass transfer, mainly: solidification and changes of the composition and the sizes of the phases involved in the mass transfer. Therefore classical techniques as spectroturbidimetry, light scattering, conductivimetry and rheology have been used. In this chapter the results obtained by using a technique that has been developed for charactering emulsions and their evolution due to mass transfer will be thoroughly described. The referred technique called DSC for Differential Scanning Calorimetry is described in the next section. Afterwards the results dealing with simple, mixed and multiple emulsions will be described.

\section{Differential scanning calorimetry for studying mass transfer within emulsions}

The test consists in submitting an emulsion sample, the volume of which being a few $\mathrm{mm}^{3}$, to a regular cooling and heating performed in a Differential Scanning Calorimeter, the volume of the cell being a few $\mathrm{mm}^{3}$. The emulsion samples are taken time to time from the mother emulsion wherein mass transfers are expected to occur at ambient temperature.

During the cooling of a pure material, the droplets dispersed in the emulsions are expected to freeze. Due to the need to the formation of a solid germ that requires a certain amount of energy, the freezing temperatures are lower than the melting ones and the theory shows they are scattered around a mean temperature $\mathrm{T}^{*}$ referred as the most probable freezing temperature of the droplets. The energy released during the droplets freezing is evidenced on the obtained freezing curve as a peak showing a bell shape if the polydispersity is low. Should the emulsion contains a rather large range of droplet sizes, the freezing curve will show more than one signal and the shape could be asymmetrical. The apex temperature of the signal that gives $\mathrm{T}^{*}$ can be correlated to the mean droplet size. On the contrary, as there is no delay in the melting phenomenon, all the droplets (whatever their size) will melt at the same temperature, which is the one observed for a bulk material. More theoretical developments of these phenomena can be found in literature (Clausse et al., 2005). Typical experimental results are given thereafter.

Figures 1 shows typical cooling curves obtained by DSC of pure water (Figure 1a) dispersed in W/O emulsions. For comparison, DSC of bulk water is given on Figure 1b. These curves represent the basic data needed to interpret the results obtained by DSC on emulsions. For a bulk material, its solidification will give a signal at a temperature higher than the one obtained for dispersed material $\left(-18^{\circ} \mathrm{C}\right.$ for bulk water and $-39^{\circ} \mathrm{C}$ for dispersed water). Between the melting temperature $T_{m}$ and the freezing temperature $T_{c}$, the material still 
liquid is said to be under cooled. The degree of undercooling is defined by $\Delta \mathrm{T}=\mathrm{T}_{\mathrm{m}}-\mathrm{T}_{\mathrm{c}}$. For water, this degree is around $20^{\circ} \mathrm{C}$ for bulk water of a few $\mathrm{mm}^{3}$ and around $40^{\circ} \mathrm{C}$ for a population of microsized droplets. Another point to stress is that the shape of the signals is also different. This can be attributed to the way the material solidifies, very rapidly in a bulk sample or progressively in a dispersed phase as it has been indicated previously.
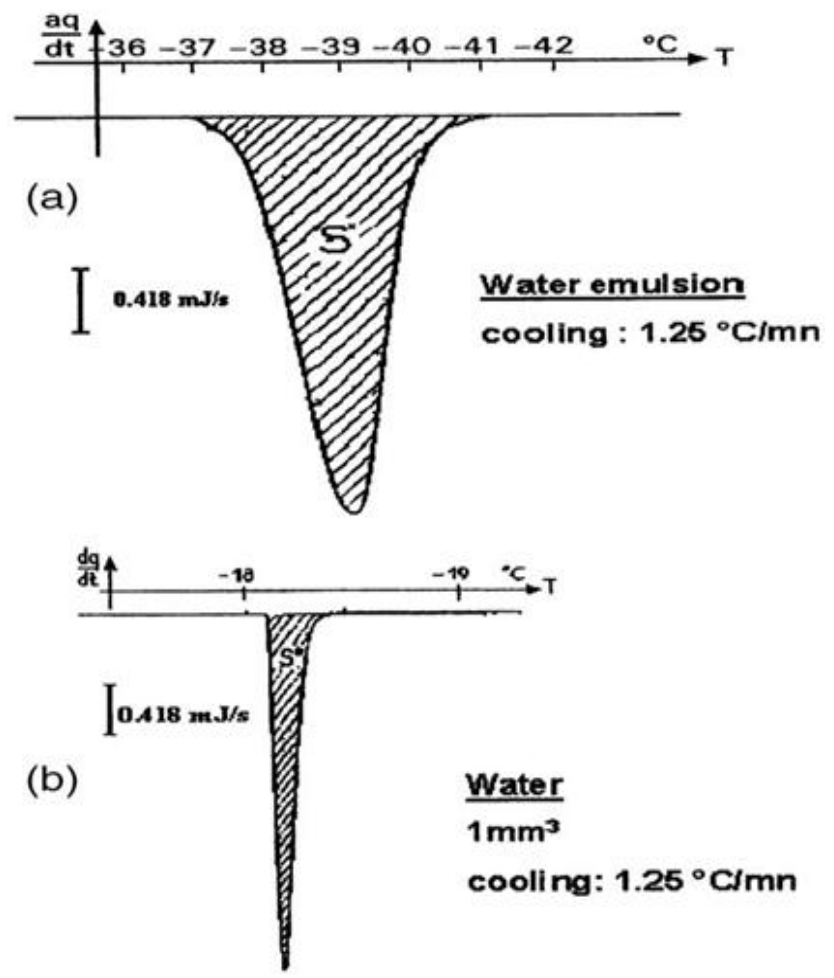

Fig. 1. Cooling curves for water dispersed in an emulsion (a) and for bulk water (b)

From the electrical power $\mathrm{dq} / \mathrm{dt}$ registers by the calorimeter it is possible to deduce the enthalpy power $\mathrm{dh} / \mathrm{dt}$ involved by the freezing or melting of the sample. On using rather low scanning rate temperature less than $2 \mathrm{~K} / \mathrm{min}$, $\mathrm{dh} / \mathrm{dt}$ can be approximated by $\mathrm{dq} / \mathrm{dt}$. Therefore by a previous calibration done with pure materials, the area of the signal correctly delimited permits to determine $\Delta \mathrm{H}$, the total heat involved in the liquid-solid transition. This quantity divided by the energy involved per mass unit $\Delta \mathrm{h}$ permits to know the mass $\mathrm{m}$ involved in the transition. $\Delta \mathrm{h}$ for the freezing is different for the melting one due to the net influence of the temperature specially for water due to a rather high difference between the values of the heat capacities of ice and liquid water. Nevertheless this quantity can be estimated from data on heat capacities values and as far comparison of areas of signals are done, this point is not a problem by itself. Furthermore when it is possible the amount of material involved in the transition can be determined by the area of the melting signal at a known temperature at which $\Delta \mathrm{h}$ is found in the literature. Should a mass transfer induces a change of the initial mass $\mathrm{m}(\mathrm{t}=0)$ of a material, the following of the area $\mathrm{A}(\mathrm{t})$ of either the 
freezing signal or the melting signal allows to evaluate the transferred material $\mathrm{z}$ or the ratio of non-transferred material y. They will be given by the following equations:

$$
\begin{gathered}
z=m(t=0)-m(t)=\frac{[\Delta H(t=0)-\Delta H(t)]}{\Delta h}=A(t=0)-A(t) \\
y=\frac{m(t)}{m(t=0)}=\frac{\Delta H(t)}{\Delta H(t=0)}=\frac{A(t)}{A(t=0)}
\end{gathered}
$$

Should the material contain additives, the cooling curves obtained will be different and dependent on the amount of solute present (Figure 2). For two compounds A+B forming solutions in all proportions and showing an eutectic point, the freezing curves show either one or two signals as it is shown on figure 2 for 6 compositions shown by dotted lines in the phases diagram $\mathrm{T}$ versus composition $\mathrm{x}$ given as molar fraction of component $\mathrm{B}$ in the solutions. Line starting from $A_{0}^{e}$ represents the A solidification points versus composition and line starting from $B_{0}^{e}$, the $B$ solidification points versus composition, $\mathrm{E}$ being the eutectic point of the binary. When a solution is dispersed within an emulsion the solidification of the droplets shows different results depending on the composition. A composition different from the eutectic point $\mathrm{E}$, separates the sequence of the events. This point indicated as $\varepsilon$ on the graph is found at the intersection of two lines that give the most probable solidification temperatures of $\mathrm{A}$ for $\mathrm{x}<\mathrm{x} \varepsilon$ and the most probable solidification temperatures of $\mathrm{B}$ for $\mathrm{x}>\mathrm{x}$. The circles mimic the contents of the droplets regards to the solid materials present. They are drawn in front of the respective signals shown by DSC. For example for droplets the composition of which being given by dotted line 2, the cooling curve shows two signals, one showing the partial solidification of A and at a lower temperature the total solidification of the droplet, namely the solidification of $\mathrm{B}$ and the solidification of the remaining A still liquid. As it can be seen on the diagram, the signals shift with the composition. The temperature of the apex of the first signal observed gives the most probable solidification temperature as it was yet described for dispersed pure material. The heating curve represented on the figure 2 by the line $1^{*}$ for the composition represented by the dotted line 1 , shows the eutectic melting followed by the progressive melting of component A until its complete dissolution when the equilibrium line is reached. This diagram is a schematic one for the case considered, solutions that can be mixed in all proportions and that show an eutectic point. In this chapter mixtures of hexadecane and tetradecane that enter in this case will be considered. Generally, especially for water + salt, the diagram is limited as far very concentrated solution in B being impossible to reach. That is the case for water $+\mathrm{NaCl}$, solutions or water +urea solutions also treated in this chapter.

For the purpose of studying mass transfer that induces changes in the composition of the droplets, only the lines that give the most probable solidification temperature of either A or $\mathrm{B}$ will be considered. This curve will be referred as the calibration curve that gives the most probable freezing temperature $\mathrm{T}^{*}$ versus the composition of the droplets. The undercooling given by the interval of temperatures between the equilibrium lines, and the lines that give the most probable solidification temperatures is not a constant as the figure lets assuming, but in fact it is changing with the composition and the drawing of the calibration curve needs to study samples of various compositions as it will be described later on. Determining the temperature from the freezing signal allows determining the composition of the droplets and therefore from the knowledge of the formulation of the emulsions and by doing a 
material balance, the amount of material transferred can be determined. When it is possible another way to follow the transfer is to determine the areas of the freezing or better the melting signals for the droplets for which the composition does not vary, the transfer being from these droplets to the other droplets of different composition. The way these determinations are done will be more thoroughly described in the sections dealing with.

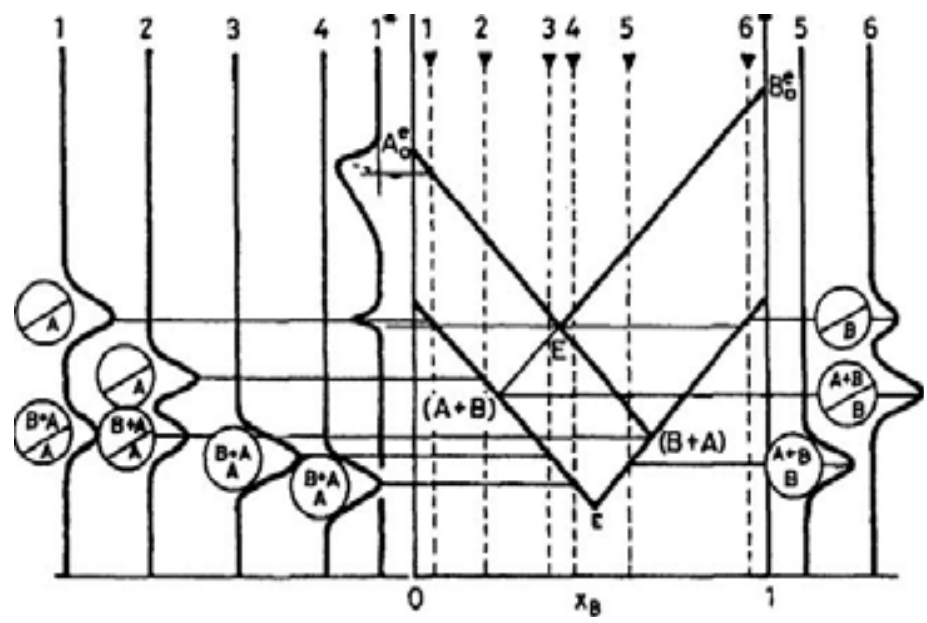

Fig. 2. Cooling and heating curves for a solution $A+B$ dispersed within an emulsion

To summarize two ways for quantifying the mass transfer will be used. One from the determination of $y$ (equation 2) and the other one from the calibration curve $\mathrm{T}^{*}$ versus the composition of the droplets made of $\mathrm{A}+\mathrm{B}$ due to the transfer.

\section{Mass transfer within simple emulsions. Solid ripening in W/O emulsions}

An example is given by the mass transfer between yet solid droplets and still liquid ones due to under cooling phenomena. This transfer not very well known but that has to be taken into account when during the storage of the emulsion, the temperature reaches values below the melting ones, is referred as solid ripening as far the equilibrium state in these conditions is all the dispersed material solid (Clausse et al. 1999b). The other type is encountered when a material is added in the continuous phase of an emulsion. It is expected to diffuse and to react chemically with the material of the dispersed droplets. At the end a stable solid material is also obtained. Formation of solid hydrates in petroleum industry is a typical example of such a situation. It is this kind of transfer that is described thereafter.

An example of such solid ripening giving rise to the formation of a hydrate is illustrated by the study of trichlorofluoromethane $\left(\mathrm{CCl}_{3} \mathrm{~F}\right)$ hydrate formation in W/O emulsions. $\mathrm{CCl}_{3} \mathrm{~F}$ is a volatile liquid poorly soluble in water and forms a hydrate under mild conditions at $8.5^{\circ} \mathrm{C}$ and 1 bar. Therefore, $\mathrm{CCl}_{3} \mathrm{~F}$ appeared to be a good candidate in order to mimic the conditions of gas hydrate formation in W/O emulsions as a model system (Jakobsen et al. 1996; Fouconnier et al. 1999, 2006). The solid hydrate phase is formed inside the dispersed droplets as the result of a chemical reaction between $\mathrm{CCl}_{3} \mathrm{~F}$ molecules and water molecules present in the droplets. Actually, $\mathrm{CCl}_{3} \mathrm{~F}$ molecules are initially dissolved in the oily 
continuous phase and diffuse through the $\mathrm{W} / \mathrm{O}$ interface to be encapsulated by water molecules into a crystalline hydrate phase of structure II. In this chapter, it is described how to study the $\mathrm{CCl}_{3} \mathrm{~F}$ hydrate formation by DSC.

\subsection{Emulsion preparation}

The emulsions were prepared using Exxol D80 (a mixture of aliphatic and cycloaliphatic hydrocarbons from $\mathrm{C}_{10}$ to $\mathrm{C}_{13}$ ) and mixed with trichlorofluoromethane as the continuous oil phase (Fouconnier et al., 2002). The emulsifier, berol 26 (tetraoxyethylene nonyl-phenyl ether, $\left.\mathrm{C}_{9}-\mathrm{Ph}-\mathrm{E}_{4}\right)$, was added to the oil phase at a concentration of $4 \%$ by volume. The amount of $\mathrm{CCl}_{3} \mathrm{~F}$ is incorporated in the oil in stoechiometric proportion according to the hydrate formation reaction: $\mathrm{CCl}_{3} \mathrm{~F}+17 \mathrm{H}_{2} \mathrm{O} \rightarrow \mathrm{CCl}_{3} \mathrm{~F}\left(\mathrm{H}_{2} \mathrm{O}\right)_{17}$. The dispersed phase was composed of aqueous saline solutions of calcium chloride at different concentrations by weight. Nevertheless, in order to diminish the evaporation of volatile $\mathrm{CCl}_{3} \mathrm{~F}$ and also to prevent the emulsion breaking, a primary emulsion made of Exxol D80, berol 26 and the saline solution was firstly prepared. The dispersion was obtained at $10000 \mathrm{rpm}$ by means of a homogenizer Polytron PT 3000 during 10 minutes. The $\mathrm{CCl}_{3} \mathrm{~F}$ was finally added under gentle mixing to the emulsion stored at $0^{\circ} \mathrm{C}$ and kept at this temperature until utilization. The final emulsions were $60 / 40$ water to oil ratio.

\subsection{Mechanisms of hydrate formation in W/O emulsions}

Jakobsen et al. were the first to study $\mathrm{CCl}_{3} \mathrm{~F}$ hydrate formation in $\mathrm{W} / \mathrm{O}$ emulsions by dielectric spectroscopy (Jakobsen et al., 1996). During experiments, the emulsions were under constant stirring and the hydrate formation was detected with an induction period at $4.5^{\circ} \mathrm{C}$ but took place spontaneously at $3^{\circ} \mathrm{C}$. The induction period was attributed to an insufficient undercooling, a reduced contact between $\mathrm{CCl}_{3} \mathrm{~F}$ and water molecules, the energy added to the system by stirring and inhomogeneous mixing during the initial period due to the addition of $\mathrm{CCl}_{3} \mathrm{~F}$ in the emulsion. The shift of temperature between $8.5^{\circ} \mathrm{C}$ and $3^{\circ} \mathrm{C}$ was attributed to the freezing depression point due to the presence of $\mathrm{NaCl}$ in the dispersed aqueous phase and the effect of undercooling in emulsions as it has been described in section 2.

The authors modeled the kinetics of the $\mathrm{CCl}_{3} \mathrm{~F}$ formation as followed.

$$
\begin{gathered}
\mathrm{CCl}_{3} \mathrm{~F}_{\text {(oil) }} \rightarrow \mathrm{CCl}_{3} \mathrm{~F}_{\text {(aqueous phase) }} \\
\mathrm{CCl}_{3} \mathrm{~F}+17 \mathrm{H}_{2} \mathrm{O} \rightarrow \mathrm{CCl}_{3} \mathrm{~F} .\left(\mathrm{H}_{2} \mathrm{O}\right)_{17} \\
\mathrm{CCl}_{3} \mathrm{~F}+17 \mathrm{H}_{2} \mathrm{O} \Re \mathrm{CCl}_{3} \mathrm{~F} .\left(\mathrm{H}_{2} \mathrm{O}\right)_{17}
\end{gathered}
$$

The reaction (a) represents the diffusion of $\mathrm{CCl}_{3} \mathrm{~F}$ from the oil phase to the aqueous dispersed phase. The reaction (b) represents the slow formation of the hydrate considering that cavities of structure II are forming. The reaction (c) represents the autocatalytic formation of the hydrate.

Jakobsen et al. showed that the diffusion of $\mathrm{CCl}_{3} \mathrm{~F}$ molecules from the oil phase to the aqueous phase is the rate-limiting step. They also speculated that the surfactant can act as a barrier to the diffusion of the hydrate forming specie.

We also studied a similar dispersed system by DSC, $\mathrm{CaCl}_{2}$ was also used, and it is worth noting that in our conditions of study it was impossible to detect the hydrate formation 
during the cooling of the emulsions or by storing them at low temperatures for a long period. The conditions of $\mathrm{CCl}_{3} \mathrm{~F}$ hydrate formation by DSC were different from those used by Jakobsen. There was no agitation and furthermore the emulsions understudied were really stable. During the cooling of the emulsions, it was only observed the crystallization of aqueous droplets as bell shape signals at temperatures below $-40^{\circ} \mathrm{C}$ as the droplets contained salt. Hydrate formation was not detected during the cooling.

Therefore, in order to evidence the conditions of the $\mathrm{CCl}_{3} \mathrm{~F}$ hydrate formation in W/O emulsions, a study using DSC and X-ray diffraction has been undertaken (Fouconnier et al. 2006). It has been concluded that a high degree of undercooling results in a spontaneous ice formation in the droplets during cooling of the emulsions. It has been showed by X-ray diffraction that the hydrate formed during subsequent heating of the emulsions as soon as the ice was beginning to melt. A mechanism of hydrate formation based on the shell model was then proposed as illustrated in figure 3.

During the heating of the emulsion, when the ice begins to melt, the droplet can be viewed as a core of ice surrounding by a saline solution. During the progressive melting of ice, the hydrate forms leading to the formation of a shell around the droplet. When the ice is completely melts, the hydrate formation is stopped and a shell of hydrate phase is in equilibrium with a concentrated saline solution since salt does not participate to the hydrate formation. Finally, when the hydrate dissociates, the remaining saline solution is progressively diluted until reaching the initial composition of the dispersed solution when the hydrate is completely dissociated.

From this simplified model it was then possible to study the hydrate formation within $\mathrm{W} / \mathrm{O}$ emulsions and the effect of salts upon the hydrate formation.

It is described in next paragraph how to interpret the heating of DSC curves and for example, how to determine the quantity of hydrate formed.

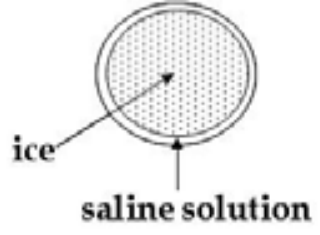

When the melting of ice begins

a)

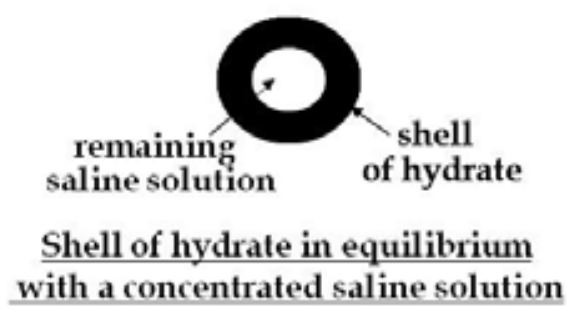

c)

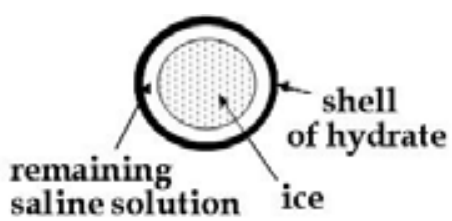

During the progressive melting of ice

b)

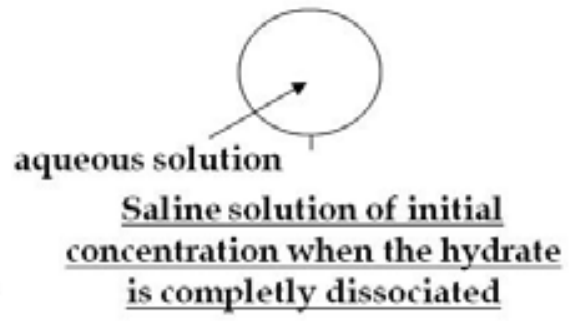

d)

Fig. 3. Schematic representation of the droplet composition at different temperatures 


\subsection{DSC measurements and determination of the amount of hydrate formed}

Figure 4 report the DSC heating curves of two emulsions with and without $\mathrm{CCl}_{3} \mathrm{~F}$ after being cooled down since $-90^{\circ} \mathrm{C}$. Both emulsions were prepared with aqueous solutions of $\mathrm{CaCl}_{2}$ at a concentration of $6.8 \mathrm{wt} \%$. On the DSC curves, the signal I at $-52^{\circ} \mathrm{C}$ is attributed to the eutectic fusion of the water-calcium chloride binary system. Signals II and III represent the progressive melting of ice as it has been described in section 2. An additional signal IV only appears for the emulsion containing $\mathrm{CCl}_{3} \mathrm{~F}$ and it is attributed to the dissociation of hydrate.

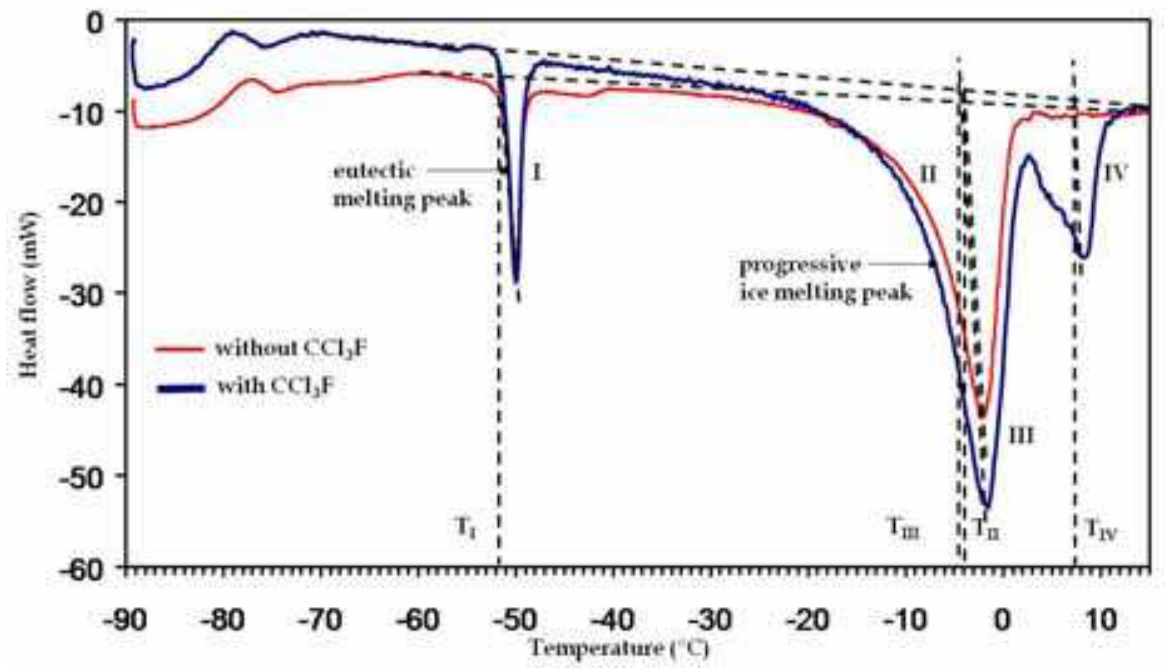

Fig. 4. DSC curves of emulsions with and without $\mathrm{CCl}_{3} \mathrm{~F}$ containing initially saline solutions of $6.8 \mathrm{wt} \% \mathrm{CaCl}_{2}$

It has been observed from the DSC and X-ray diffraction analysis that the hydrate dissociates progressively like melting of ice in presence with salt as the line $1^{*}$ of the figure 2 shows. Therefore, the temperature of hydrate dissociation has been determined as the solidliquid equilibrium temperatures of water-salt systems (Fouconnier et al. 2002).

The temperatures of the end of progressive ice melting $\left(\mathrm{T}_{\mathrm{II}}, \mathrm{T}_{\mathrm{III}}\right)$ and the hydrate dissociation temperature $\left(\mathrm{T}_{\mathrm{IV}}\right)$ are obtained by taking the intersection between the baseline of DSC curves and a line parallel to the greatest slope line of the eutectic peak, going through the node of each endothermic peak. The corresponding temperatures are given by the projection of the intersection points (dotted lines) on the temperature axis. Doing so, the temperatures of the end of the melting of ice (or solid-aqueous solution equilibrium temperature) are of $4.7^{\circ} \mathrm{C}$ and $-4^{\circ} \mathrm{C}$ for the emulsion with and without $\mathrm{CCl}_{3} \mathrm{~F}$ respectively. The temperature of the hydrate dissociation is $7.5^{\circ} \mathrm{C}$. It can be observed that the temperature of the end of ice melting in reference to the emulsion containing $\mathrm{CCl}_{3} \mathrm{~F}$ is slightly lower than the one of the emulsion without $\mathrm{CCl}_{3} \mathrm{~F}$. This shift of temperature is attributed to the formation of hydrate. When hydrate forms, water molecules are engaged in the hydrate structure resulting in the concentration of the saline solution inside the emulsion droplets.

Once stated how to determine the temperatures of the hydrate dissociation as function of salt concentration and by considering that the hydrate phase is in equilibrium with a 
remaining saline solution when ice is completely melted, it is possible to carry out a mass balance using the temperatures of ice-aqueous solution equilibrium and by using the water$\mathrm{CaCl}_{2}$ equilibrium curve. Such mass balance is illustrated by the study of an emulsion containing a dispersed $\mathrm{CaCl}_{2}$ aqueous solution of $20 \mathrm{wt} \%$. For comparison, the equivalent emulsion without $\mathrm{CCl}_{3} \mathrm{~F}$ was also studied.

Figure 5a presents the DSC curves for emulsions with and without $\mathrm{CCl}_{3} \mathrm{~F}$. Figure $5 \mathrm{~b}$ shows the water- $\mathrm{CaCl}_{2}$ equilibrium curve.

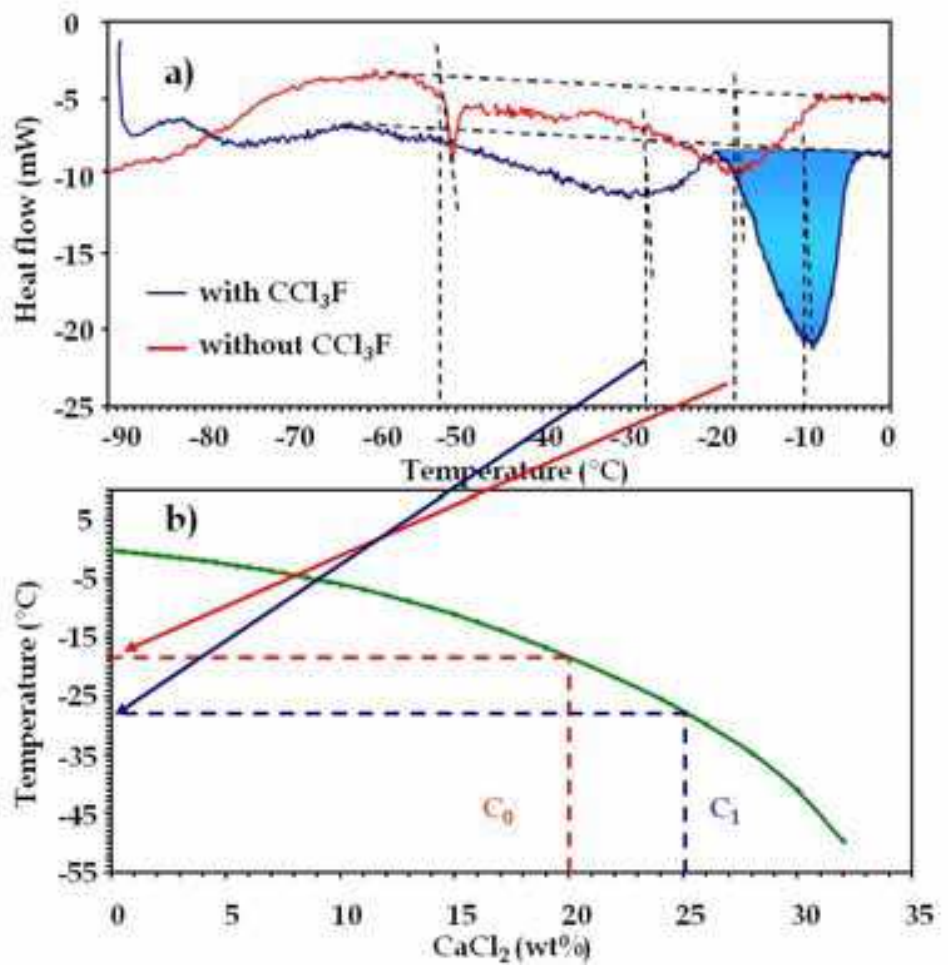

Fig. 5. a) DSC curves of emulsions with and without $\mathrm{CCl}_{3} \mathrm{~F}$ containing initially saline solutions of $20 \mathrm{wt} \% \mathrm{CaCl}_{2}$. b) Equilibrium curve of the water- $\mathrm{CaCl}_{2}$ binary system

The temperatures of ice-saline solution equilibrium were determined as described previously and are $\mathrm{T}=-28^{\circ} \mathrm{C}$ for the emulsion containing $\mathrm{CCl}_{3} \mathrm{~F}$ and $\mathrm{T}=-18^{\circ} \mathrm{C}$ for the emulsion without $\mathrm{CCl}_{3} \mathrm{~F}$. These temperatures are then reported on the equilibrium curve of the water- $\mathrm{CaCl}_{2}$ system. Therefore, $\mathrm{T}=-28^{\circ} \mathrm{C}$ corresponds to a hydrate phase in equilibrium with a saline solution of $25 \mathrm{wt} \%$ of $\mathrm{CaCl}_{2}$ and $\mathrm{T}=-18^{\circ} \mathrm{C}$ corresponds to the dispersed saline solution of $20 \mathrm{wt} \%$ used for the emulsion preparation.

On the other hand, the mass fraction $\varphi$ of aqueous phase of the emulsion was needed to carry out the mass balance. According to the formulation of the emulsion, the mass fraction $\varphi$ is given by the following relation where $\mathrm{m}_{\text {aqueous, }} \mathrm{E}$ and $\mathrm{m}_{\mathrm{oil}}$ phase, $\mathrm{E}$ are the mass of the dispersed saline solution and the mass of the oil phase $\left(\mathrm{CCl}_{3} \mathrm{~F}+\right.$ berol + Exxol D80) respectively. 


$$
\varphi=\frac{m_{\text {aqueous phase }, E}}{m_{\text {oil phase }, E}+m_{\text {aqueous phase }, E}}=0.624
$$

The emulsion sample was also weighted before introducing it inside the calorimeter head. In this example, the mass sample was $m_{s}=0.2111 \mathrm{~g}$. From this data it was possible to determine the mass of the aqueous phase inside the emulsion sample as

$$
m_{\text {aqueous phase }, S}=m_{S} \times \varphi=0.1317 \mathrm{~g}
$$

which finally gave $0.1054 \mathrm{~g}$ of water in the emulsion sample.

Finally, by knowing that the saline solution concentrated from $20 \mathrm{wt} \%$ to $25 \mathrm{wt} \%$ due to hydrate formation, it can be deduced that $75 \%$ of mass water does not participate to the reaction. Therefore, the number of mole of water engaged in the hydrate structure can be deduced from the equation (5).

$$
n_{\text {water }}=\frac{m_{\text {water engaged }}}{M_{\text {water }}}=\frac{0.1054 \times(1-0.75)}{18}=1.4638 \times 10^{-3} \mathrm{~mol}
$$

The mass of hydrate crystallized $m_{\text {hydrate }}$ during the progressive melting of ice is calculated via equation (6) considering structure II of hydrate $\left(\mathrm{CCl}_{3} \mathrm{~F} .\left(\mathrm{H}_{2} \mathrm{O}\right)_{17}\right)$.

$$
m_{\text {hydrate }}=\frac{n_{\text {water engaged }}}{17} \times M_{\text {hydrate }}=3.8190 \times 10^{-2} \mathrm{~g}
$$

where $\mathrm{M}_{\text {hydrate }}=443.5 \mathrm{~g} \cdot \mathrm{mol}^{-1}$ is the molar weight of the $\mathrm{CCl}_{3} \mathrm{~F}$ hydrate.

Furthermore, it was also possible to determine the hydrate dissociation energy. The hydrate dissociation peak was integrated via the calorimeter software. Therefore, the corresponding energy released during the dissociation of hydrate divided by the mass calculated as described before, gave the specific dissociation energy of the hydrate. In this example, the specific dissociation energy was determined as $166.1 \mathrm{~J} \cdot \mathrm{g}^{-1}$ at $-10^{\circ} \mathrm{C}$ (Fouconnier et al. 2002).

The $\mathrm{CCl}_{3} \mathrm{~F}$ hydrate model has been also used to understand the mechanism of hydrate formation in emulsion (Dalmazzone et al. 2002). It has been demonstrated that DSC is a suitable technique to detect the hydrate formation via the solid-liquid transitions involved and to predict the hydrate formation zone by the determining the temperature of hydrate dissociation as a function of salt concentration.

This model has been used to study methane hydrate formation in drilling muds (Dalmazzone et al. 2002). It has been demonstrated that the $\mathrm{CCl}_{3} \mathrm{~F}$ hydrate formation can modeled gas hydrate formation in applied systems. Studies of gas hydrate formation by DSC can be found in literature (Koh et al, 2002; Karrat \& Dalmazzone, 2003; Lachance et al., 2008; Dalmazzone et al. 2009, Davies et al., 2009) and it must be also emphasized that DSC has been developed to be directly used in offshore in order to predict the zone of gas hydrate formation (Le Parlouër et al. 2004).

\section{Mixed emulsions}

Mixed emulsions are obtained by gently mixing two simple emulsions containing droplets of different composition (Figure 6). Mixed emulsions are well-suited model systems to study 
transfer mechanisms across liquid membranes (Li, 1968; Colinart et al., 1984; Noble \& Stern, 1995). For instance, these systems allow to model transport processes between two oil phases separated by an aqueous membrane in the case of oil-in-water $(\mathrm{O} / \mathrm{W})$ emulsions and between two aqueous phases separated by an organic membrane in the case of water-in-oil (W/O) emulsions.

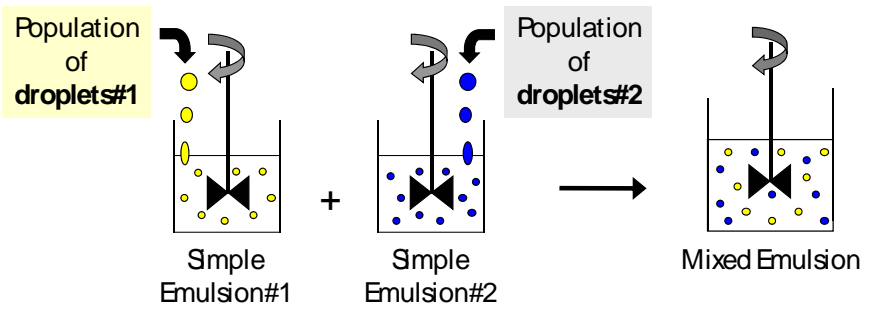

Fig. 6. Schematic representation of mixed emulsion preparation

The mass transfers due to a gradient composition between the different phases present in the emulsion lead to a modification of the composition of the droplets by dilution and the decrease of the amount of pure droplets by transfer (Figure 7).

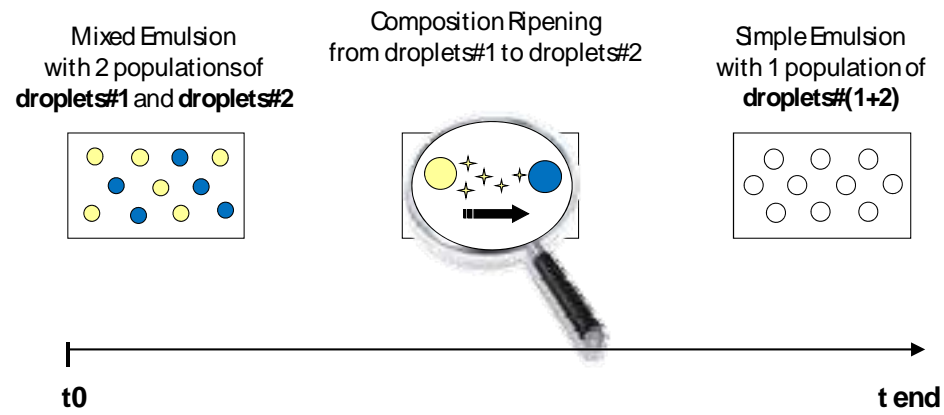

Fig. 7. Schematic representation of the droplet composition with time in mixed emulsion

Many studies evidenced the composition ripening that takes place in mixed emulsion by measuring the rate of mass exchange between two kinds of water droplets with solute dispersed in oil media or two populations of hydrocarbon droplets dispersed in aqueous phase. In the case of this study, we propose to describe in this chapter the pure water mass transfer to aqueous solute solution droplets in $\mathrm{W} / \mathrm{O}$ mixed emulsion and the transfer of tetradecane to hexadecane droplets in $\mathrm{O} / \mathrm{W}$ mixed emulsion.

\subsection{DSC measurements and determination of water mass transfer in W/O mixed emulsions}

The goal of the work reported (Clausse et al., 1995; 1999; 2008; Sacca et al., 2008) is to evidence the composition ripening that takes place in $\mathrm{W} / \mathrm{O}$ mixed emulsions and to measure the rate of water exchange between pure water droplets and aqueous solute (urea or $\mathrm{NaCl}$ ) droplets dispersed in oil medium. The effect of the emulsion stabilizing agent, as emulsifier or particles, on the kinetics of water transfer was investigated and discussed. 


\subsubsection{Emulsion preparation}

The $\mathrm{W} / \mathrm{O}$ mixed emulsions, for which water transfer is expected, were obtained by a simple manual mixing of equal masses of two W/O simple emulsions. First, W/O simple emulsions were made of $20 \mathrm{wt} \%$ (or $30 \mathrm{wt} \%$ ) of pure water droplets or $20 \mathrm{wt} \%$ (or $30 \mathrm{wt} \%$ ) of aqueous solute solution droplet dispersed in continuous phase consisting in variable mixtures of paraffin oil and pure vaseline paste. The aqueous solution consists in a urea solution (concentration of $20 \mathrm{wt} \%$ or $30 \mathrm{wt} \%$ ) or a $\mathrm{NaCl}$ solution (concentration of $20 \mathrm{wt} \%$ ). The emulsification was realized with a high speed homogeneizer at $50^{\circ} \mathrm{C}-60^{\circ} \mathrm{C}$ due to the higher viscosity of the aqueous solutions compared to pure water. To study the influence of the stabilizing agent, the $\mathrm{W} / \mathrm{O}$ simple emulsions were stabilized employing different surfactants in the oil continuous phase, as the lipophilic lanolin emulsifier ( $8 \mathrm{wt} \%)$ and the nonionic Span 80 surfactant (3 wt\%). To study the influence of solid particles, the W/O simple emulsions were solely stabilized by hydrophobic Aerosil R711 silica particles (0.1 $\mathrm{wt} \%$ to $3 \mathrm{wt} \%)$. Then, the $\mathrm{W} / \mathrm{O}$ mixed emulsion was obtained by mixing equal masses of the $\mathrm{W} / \mathrm{O}$ simple emulsions prepared in the same conditions and with the same stabilizing agent. The $\mathrm{W} / \mathrm{O}$ resultant mixed emulsion is a mixture of $10 \mathrm{wt} \%$ (or $15 \mathrm{wt} \%$ ) of pure water and $10 \mathrm{wt} \%$ (or $15 \mathrm{wt} \%$ ) of aqueous solute solution droplets dispersed in oil media.

\subsubsection{DSC measurements - results and discussion}

In the case of $\mathrm{W} / \mathrm{O}$ mixed emulsion constituted at time zero of two kinds of water droplets, two broad exothermic peaks are observed on DSC curves, corresponding to the crystallization of pure water droplets and of aqueous solution of solute droplets.

In the case of $\mathrm{W} / \mathrm{O}$ mixed emulsions containing pure water droplets and aqueous urea solution droplets stabilized by lanolin surfactant, the DSC cooling curves (Figure 8) indicate two solidification peaks corresponding to the freezing signal I of pure droplets at $\mathrm{T}^{*}=-39^{\circ} \mathrm{C}$ (Figure 8a) and the freezing signal II of aqueous urea solution droplets with a concentration of $30 \mathrm{wt} \%$ at $\mathrm{T}^{*}=-60^{\circ} \mathrm{C}$ (Figure $8 \mathrm{~b}$ ). DSC cooling curves point out a noticeable decrease with time of the signal I area characteristic of pure water droplets freezing (Figure 8c;d). In addition, DSC cooling curves show a shift with time towards higher temperature of the signal II corresponding to the solidification of water+urea droplets. Therefore these results evidence that there is no urea transfer and that water has been transported from the pure water droplets towards the water+urea droplets, causing their dilution, according to the calibration curve of this system reported on Figure 9. Finally, only one signal at around $\mathrm{T}=-48^{\circ} \mathrm{C}$ is observed $65 \mathrm{~min}$ after the mixing and no more evolution has been observed after that time (Figure 8e). This unique signal assumed that there are no more pure water droplets whereas the water+urea droplets are still present and their dilution having reached a maximum. From the knowledge of the dependence of the water+urea droplets freezing temperature versus the urea composition (Figure 9), it was deduced that the unique signal observed at $\mathrm{T}^{*}=-48^{\circ} \mathrm{C}$ is characteristic of the freezing of $15 \mathrm{wt} \%$ urea solution droplets. This final composition is in agreement with the initial $\mathrm{W} / \mathrm{O}$ mixed emulsion obtained by mixing equal masses of each $\mathrm{W} / \mathrm{O}$ simple emulsion containing 30\% pure water of droplets and 30\% of aqueous urea solution droplets. The evolution of pure water moles numbers in mixed emulsion was deduced from the surface area of the solidification signal I of pure water (using the Equation 2) (Figure 10).

It appears that the transfer is rather fast at the beginning in agreement which the fact that the gradient of concentration is maximum at $t=0$. Afterwards the experimental results obtained from four different emulsions are scattered in a relative large range that shows the problem of reproducibility. More controlled size droplets would certainly improve the reproducibility. 


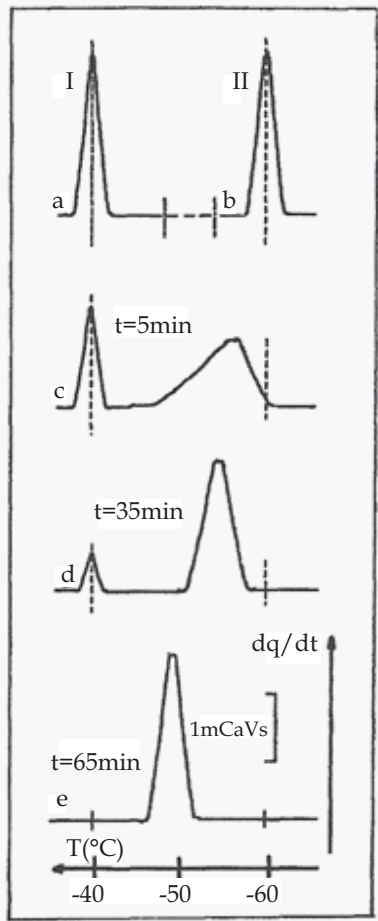

Fig. 8. DSC cooling curves of W/O mixed emulsion with pure water droplets and water+urea droplets dispersed in oil media at successive time intervals c) $t=5 \mathrm{~min}$; ) $\mathrm{t}=35 \mathrm{~min}$; e) $\mathrm{t}=65 \mathrm{~min}$

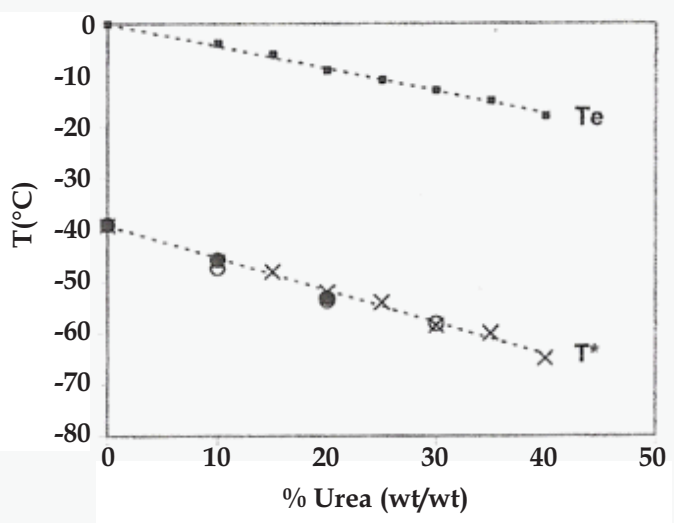

Fig. 9. Freezing temperature of urea solution versus urea concentration. Te: equilibrium freezing temperature of the urea solution in bulk; $T^{*}$ : most probable freezing temperature of the micro-sized droplets of urea solution dispersed in oil media 


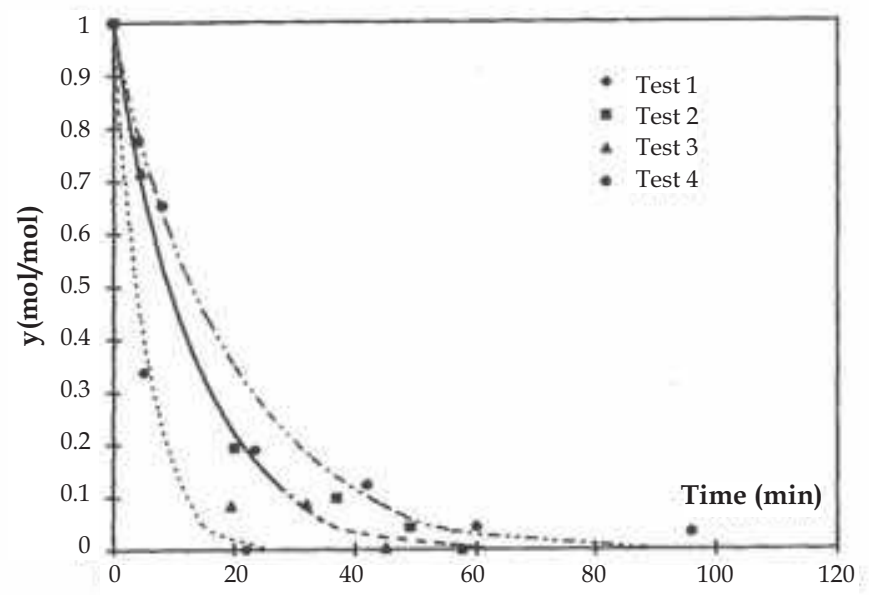

Fig. 10. Ratio y of pure water moles numbers non-transferred in $\mathrm{W} / \mathrm{O}$ mixed emulsion with pure water droplets and water+urea droplets dispersed in oil media versus time

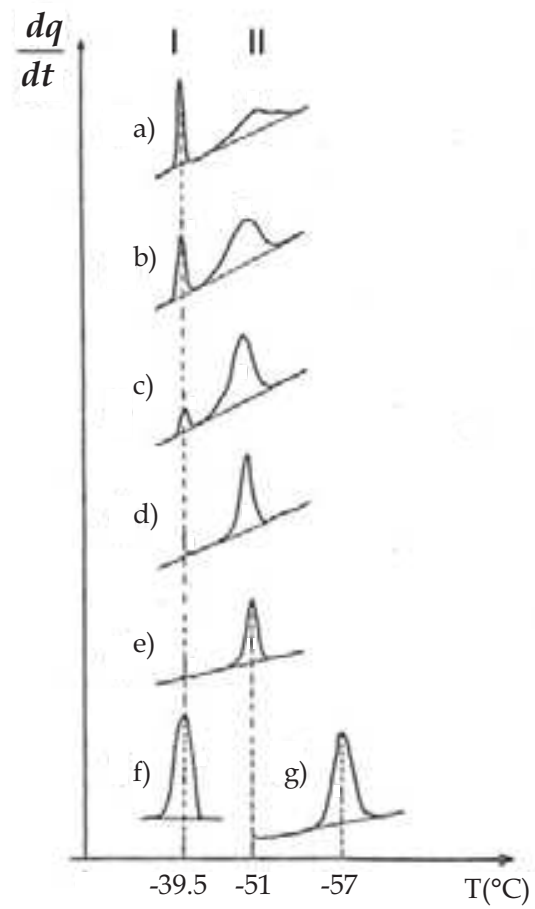

Fig. 11. DSC cooling curves of W/O mixed emulsion with pure water droplets and water $+\mathrm{NaCl}$ droplets dispersed in oil media at successive time intervals a) $t=2 \mathrm{~min}$; b) $\mathrm{t}=25 \mathrm{~min}$; ) $\mathrm{t}=43 \mathrm{~min}$; ) $\mathrm{t}=62 \mathrm{~min}$; e) $\mathrm{t}=82 \mathrm{~min}$ 
In the case of $\mathrm{W} / \mathrm{O}$ mixed emulsions containing pure water droplets and aqueous $\mathrm{NaCl}$ solution droplets stabilized by lanolin surfactant, the DSC cooling curves (Figure 11) indicate a solidification signal $\mathrm{I}$ at $\mathrm{T}^{*}=-39.5^{\circ} \mathrm{C}$ corresponding to freezing of pure water droplet (Figure 11f) and a solidification signal II relative to the freezing of aqueous $\mathrm{NaCl}$ solution droplets with a concentration of $20 \mathrm{wt} \%$ at $\mathrm{T}^{*}=-67^{\circ} \mathrm{C}$ (Figure $11 \mathrm{~g}$ ). With time, DSC cooling curves show the area of the solidification signal I of pure water droplets decreases whereas the freezing signal II appears to broaden first and then to be more and more narrow (Figure 11a-e). Therefore these results evidence the decrease of the amount of pure water droplets in mixed emulsion by a dilution of the water $+\mathrm{NaCl}$ droplets due to water coming from the pure water droplets. When the DSC cooling curves do not change any longer after $82 \mathrm{~min}$, the signal I has practically disappeared and a well defined signal II observed at around $\mathrm{T}^{*}=-51^{\circ} \mathrm{C}$ is noticeable (Figure 11e). This unique signal evidence that the complete water mass transfer is achieved: no more pure water droplets are still present and the water $+\mathrm{NaCl}$ droplets are diluted as much as possible. From the knowledge of the phase diagram of the water $+\mathrm{NaCl}$ emulsified system, and the melting temperature of the final droplets population, it was deduced that the unique signal observed at $\mathrm{T}^{*}=-51^{\circ} \mathrm{C}$ is characteristic of the freezing of $10 \mathrm{wt} \%$ aqueous $\mathrm{NaCl}$ solution droplets. This final composition is in agreement with the formulation of the $\mathrm{W} / \mathrm{O}$ mixed emulsion. The evolution of the percentage of pure water moles numbers in mixed emulsion was deduced from the surface area of the solidification signal I of pure water (using the Equation 2) (Figure 12).

In that case as well, it appears that the transfer is rather fast at the beginning. Furthermore, the time involved to reach equilibrium is very close to the one observed for the water+urea system, around $60 \mathrm{~min}$.

In the case of $\mathrm{W} / \mathrm{O}$ mixed emulsions containing pure water droplets and aqueous urea solution droplets stabilized by hydrophobic silica particles instead of a surfactant, the DSC curves (Figure 13) indicate a solidification signal $\mathrm{I}$ at $\mathrm{T}^{*}=-37^{\circ} \mathrm{C}$ very close to what was observed for the freezing of pure droplets (Figure 13a) and a solidification signal II at $\mathrm{T}^{*}=-52.6^{\circ} \mathrm{C}$ characteristic of the freezing of aqueous urea solution droplets with a

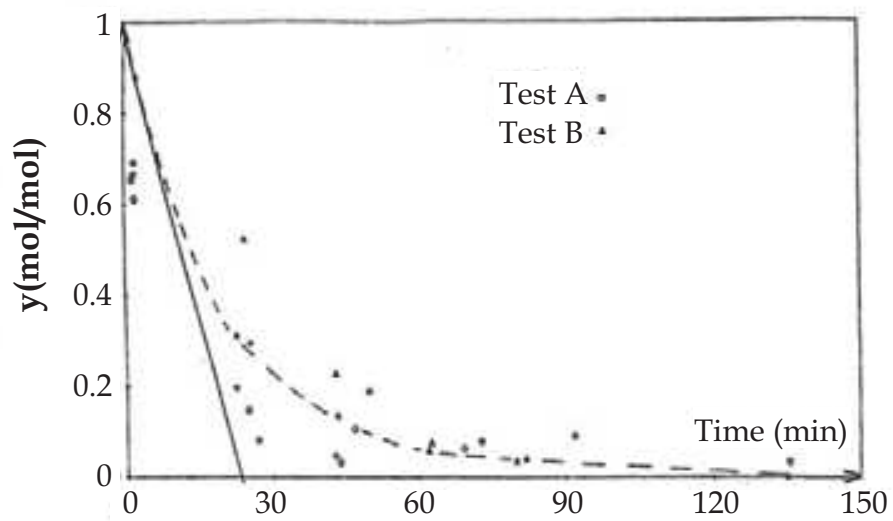

Fig. 12. Ratio y of pure water moles numbers non-transferred in $\mathrm{W} / \mathrm{O}$ mixed emulsion with pure water droplets and water $+\mathrm{NaCl}$ droplets dispersed in oil media, versus time 
concentration of $20 \mathrm{wt} \%$ (Figure 13b). DSC curves show that the evolution of the solidification signal occurs similarly to what is observed in the case of W/O mixed emulsions stabilized by a surfactant. Therefore these results evidence that aqueous urea solution droplets are diluted by the transfer of water from pure water droplets which progressively disappear from the mixed emulsion, in agreement with the previous studies presented. DSC cooling curves show no modification of the unique solidification peaks observed from $3 \mathrm{~h} 15 \mathrm{~min}$ (Figure 13e) characteristic of the complete water mass transfer. Similar experiments were performed on $\mathrm{W} / \mathrm{O}$ mixed emulsions prepared in the same condition but containing pure water droplets and aqueous urea solution droplets stabilized by the nonionic Span 80 surfactant. Same evolutions of the solidification signals are observed, but the unique solidification peaks resulting for complete water mass transfer is observed after 1 hour of evolution.

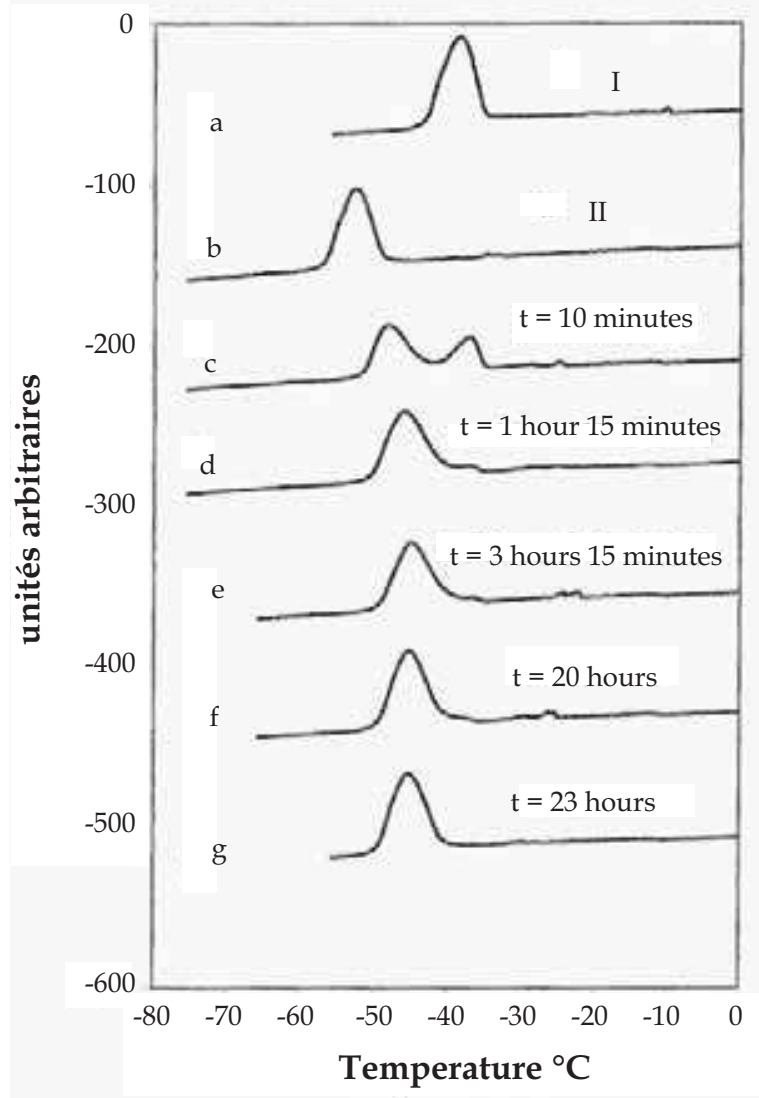

Fig. 13. DSC cooling curves of W/O mixed emulsion with pure water droplets and water+urea droplets dispersed in oil media and stabilized by hydrophobic silica particles at successive time intervals a) corresponding $\mathrm{W} / \mathrm{O}$ simple emulsion of water+urea droplets at $t=0 ; b)$ corresponding W/O simple emulsion of pure water droplets; c) $t=10 \mathrm{~min} ; d) t=1$ hours 15 min; e) $t=3$ hours 15 min; $f$ ) $t=20$ hours; $g$ ) $t=23$ hours 
This work shows a water mass transfer through the oil media from the pure water droplets to the aqueous droplets containing a solute, causing their dilution. The transfer mechanism found is in agreement with the solution-diffusion model. This mechanism supposed that water can be solubilized in the oil medium and can also diffuse in this oil medium due to the composition discrepancy between the droplets that creates a chemical potential gradient. According to thermodynamic considerations, water transfer is expected to transfer from pure water droplets (highest water chemical potential) towards water+solute droplets (lowest water chemical potential), and not the reverse. The results show that the characteristic time scale for water transport through the oil media can span about one hour in presence of surfactant. The kinectics of composition ripening seems to depend on parameters of emulsion formulation as the surfactant type and concentration, the solute type and concentration, and the presence of solid particles in the oil media. The mass transfer process is attributed to the great exchange area available in the emulsion and furthermore to the essential presence of surfactants. Although, the role of these parameters is not yet clearly established. These results evidence that the presence of silica particles in the oil media does not stop but slow down the water mass transfer, in comparison to a surfactant. These results suggest that the mechanism of mass transfer in presence of solid particles might be different of the solution-diffusion model previously proposed.

\subsection{DSC measurements and determination of tetradecane mass transfer in $\mathrm{O} / \mathrm{W}$ mixed emulsion}

The objective of the work presented (Avendano-Gomez et al., 2000; Avendano-Gomez, 2002; Clausse et al., 2002b; Drelich, 2009) is to study the composition ripening that takes place in $\mathrm{O} / \mathrm{W}$ mixed emulsions and to measure the rate of oil exchange between $\mathrm{n}$-tetradecane and n-hexadecane droplets dispersed in aqueous phase. The influence of surfactant concentration, surfactant nature, amount of salt and presence of solid particles on the rate of oil exchange is also studied and discussed.

\subsubsection{Emulsion preparation}

The $\mathrm{O} / \mathrm{W}$ mixed emulsion was prepared by gently mixing two $\mathrm{O} / \mathrm{W}$ simple emulsions. Firstly, O/W simple emulsions of tetradecane and n-hexadecane were prepared separately with a concentration of $40 \mathrm{wt} \%$ of the oil phase with the same surfactant type and concentration and homogenized with a high speed blender at $20000 \mathrm{rpm}$. To study the influence of the surfactant, the $\mathrm{O} / \mathrm{W}$ simple emulsions were stabilized employing different surfactant aqueous systems, as the non ionic surfactant Tween 20 and the ionic surfactant Brij 35. The different surfactant aqueous systems were prepared with two surfactant concentrations of $2 \mathrm{wt} \%$ and $4 \mathrm{wt} \%$, corresponding to a higher concentration than their respective critical micellar concentration. To study the influence of the presence of salt, the $\mathrm{O} / \mathrm{W}$ simple emulsions were prepared with aqueous solution containing an amount of $\mathrm{NaCl}(1 \mathrm{wt} \%$ and $2 \mathrm{wt} \%)$ added to the Tween 20 surfactant $(2 \mathrm{wt} \%)$. To study the influence of solid particles, the $\mathrm{O} / \mathrm{W}$ simple emulsions were stabilized by a mixture of hydrophilic Aerosil A200 (2 wt\%) and hydrophobic Aerosil R711 (2 wt\%) silica particles. Then, the $\mathrm{O} / \mathrm{W}$ mixed emulsion was obtained by mixing equal masses of the $\mathrm{O} / \mathrm{W}$ simple emulsions. The $\mathrm{O} / \mathrm{W}$ resultant mixed emulsion is a mixture of $15 \mathrm{wt} \%$ of pure n-tetradecane and $15 \mathrm{wt} \%$ of pure n-hexadecane droplets dispersed in $70 \mathrm{wt} \%$ of surfactant aqueous phase. 


\subsubsection{DSC measurements - results and discussion}

In the case of $\mathrm{O} / \mathrm{W}$ mixed emulsion constituted at time zero of two populations of oil droplets of different nature, two broad exothermic peaks are observed on DSC curves, corresponding to the crystallization of each population of oil droplets.

In the case of $\mathrm{O} / \mathrm{W}$ emulsions containing n-tetradecane droplets and n-hexadecane droplets stabilized by a surfactant, the DSC curves (Figure 14) indicate a first broad exothermic signal I at $\mathrm{T}^{*}=-2^{\circ} \mathrm{C}$ for the solidification of the n-hexadecane droplets, a second broad exothermic signal II at $\mathrm{T}^{*}=-17^{\circ} \mathrm{C}$ corresponding to the freezing of the n-tetradecane droplets, and a narrow exothermic peak at $\mathrm{T}_{\mathrm{c}}=-22^{\circ} \mathrm{C}$ related to the crystallization of the aqueous continuous phase. DSC curves (Figure 15) show an evolution of the two oil solidification peaks with time: an area reduction of the solidification signal II of pure tetradecane droplets and a displacement of the solidification signal I of n-hexadecane towards lower temperatures. The area reduction of the solidification peak II of pure n-tetradecane droplets is related to the amount decrease of pure n-tetradecane droplets with time. The displacement of the solidification signal I of n-hexadecane droplets towards lower temperature is related to the composition modification of the n-hexadecane droplets by the n-tetradecane dilution with time, according to the calibration curve reported on Figure 16. These evolutions evidence a preferential and global oil exchange from the tetradecane droplets towards the n-hexadecane droplets. In addition, the DSC curves reveal only one solidification peak and no change in the crystallization temperature of the dispersed phase obtained after some hours of emulsion evolution. This unique signal suggests that the mass transfer between the oils droplets is complete. The crystallization temperature of the last unique signal is observed at around $\mathrm{T}^{*}=-10^{\circ} \mathrm{C}$ and corresponds to a composition of $50 \%$ in mass of n-hexadecane in the droplets according the calibration curve (Figure 16). The initial $\mathrm{O} / \mathrm{W}$ mixed emulsion containing the same mass ratio of tetradedacne/n-hexadecane, the resulting composition due to a mixture between the tetradecane and the n-hexadecane droplets is $50 \%$ of $n$-hexadecane. Therefore, the final n-hexadecane composition within the

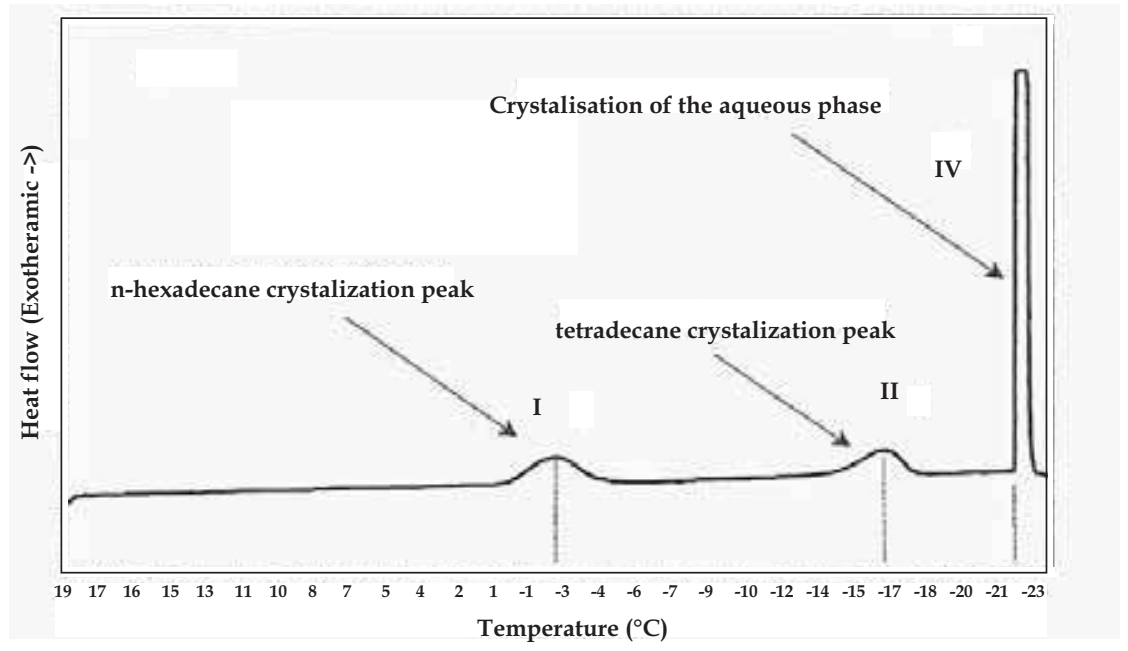

Fig. 14. DSC curves of solidification of $\mathrm{O} / \mathrm{W}$ mixed emulsion with n-tetradecane droplets and $\mathrm{n}$-hexadecane droplets dispersed in aqueous phase 
droplets is in agreement with the value expected. The results indicate the time to reach the total oil transfer is 16 hours with $2 \%$ of Brij 35 and only 3 hours and 30 minutes with $4 \%$ of Brij 35 (not represented), 24 hours with $2 \%$ of Tween 20 (Figure 15a right) and only 6 hours with $4 \%$ of Tween 20 (Figure 15a left). The result shows that the mass transfer is achieved after $31 \mathrm{~h}$ and 30 minutes of evolution when droplets are dispersed in aqueous phase containing $2 \%$ of $\mathrm{NaCl}$ and $2 \%$ of Tween 20 (Figure 15b). The evolution of pure tetradecane moles numbers in mixed emulsion was deduced from the surface area of the solidification signal I of pure tetradecane (using the Equation 2) (Figure 17).
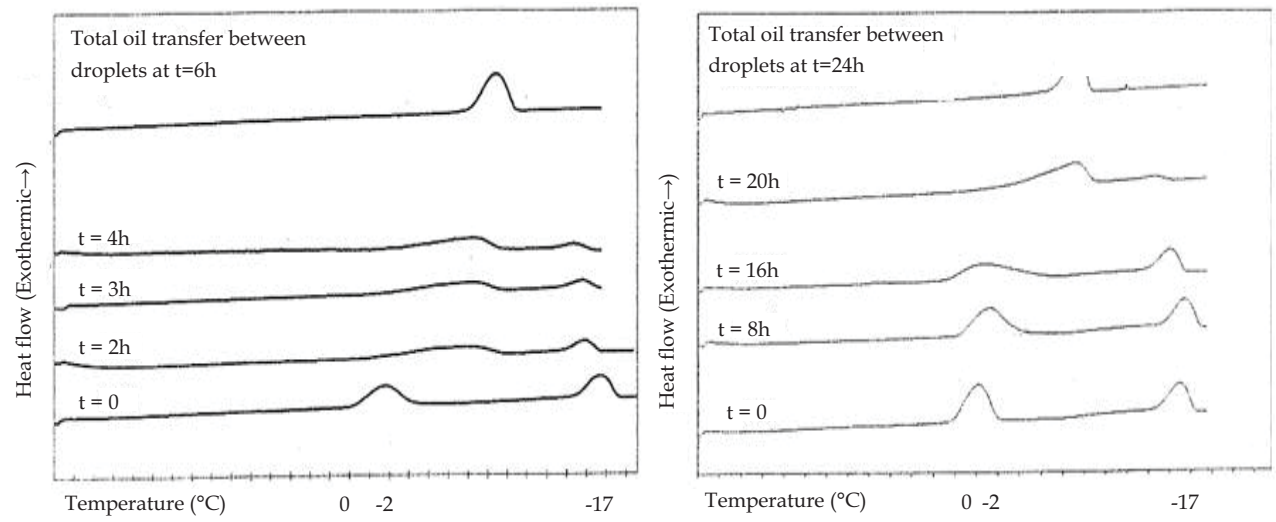

(a)

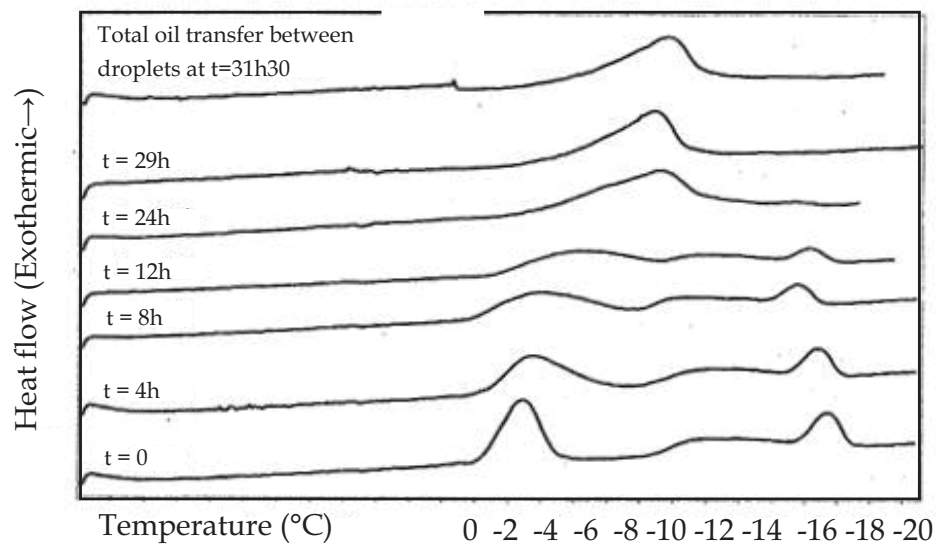

(b)

Fig. 15. DSC curves showing the solidification of $\mathrm{O} / \mathrm{W}$ mixed emulsion containing $15 \mathrm{wt} \%$ of n-tetradecane droplets and $15 \mathrm{wt} \%$ of n-hexadecane droplets dispersed in an aqueous phase with a) 4 wt\% (left) and $2 \mathrm{wt} \%$ (right) of Brij 35, b) $4 \mathrm{wt} \%$ (left) and $2 \mathrm{wt} \%$ (right) of Tween 20 surfactant and c) $2 \mathrm{wt} \%$ of $\mathrm{NaCl}$ and $2 \mathrm{wt} \%$ of Tween 20 surfactant, at successive time intervals 


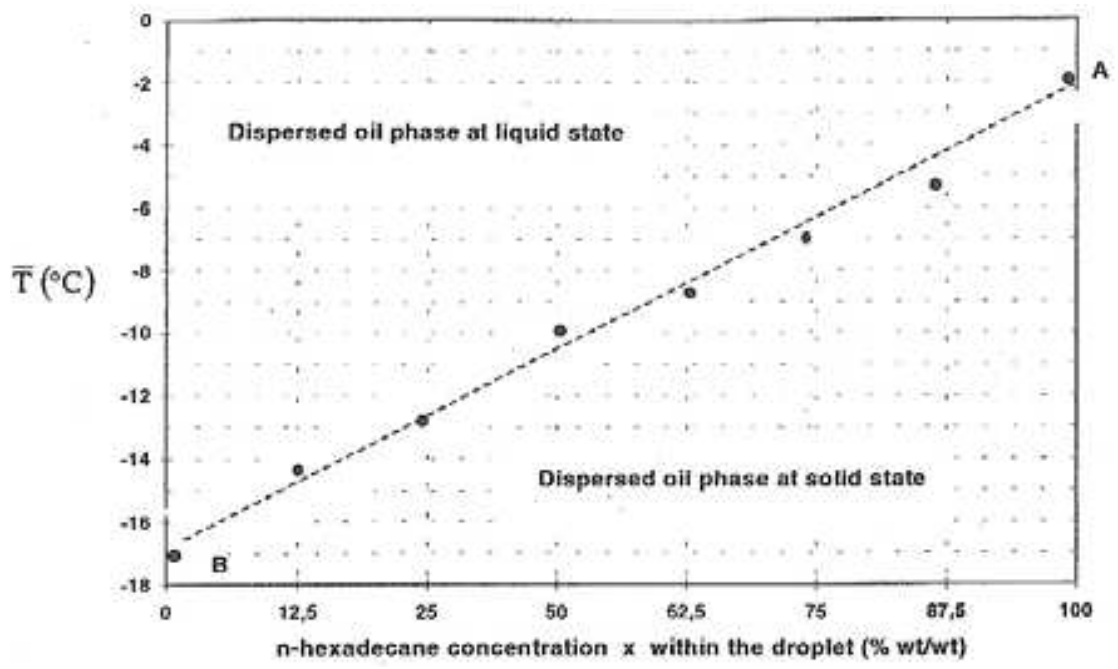

Fig. 16. Calibration curve giving the most probable crystallization temperature as a function of $n$-tetradecane/n-hexadecane oil droplets dispersed in aqueous phase

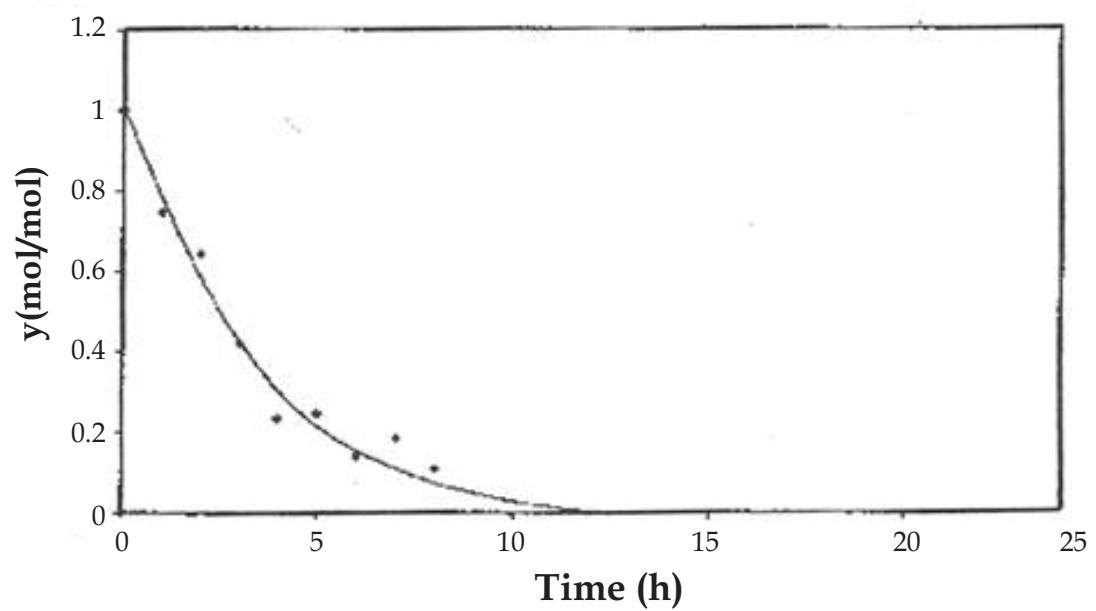

Fig. 17. Ratio y of pure tetradecane moles numbers non-transferred in $\mathrm{O} / \mathrm{W}$ mixed emulsion with n-tetradecane droplets and n-hexadecane droplets dispersed in aqueous surfactant phase versus time

In the case of $\mathrm{O} / \mathrm{W}$ emulsions stabilized by silica particles, the DSC curves (Figure 18) show no evolution of the solidification signals of oil droplets observed during a time scale of 13 days. These results suggest that no modification of the droplets oil composition occurred during this time scale. These evolutions evidence silica particles not permit to a mass transfer between tetradecane and n-hexadecane. 


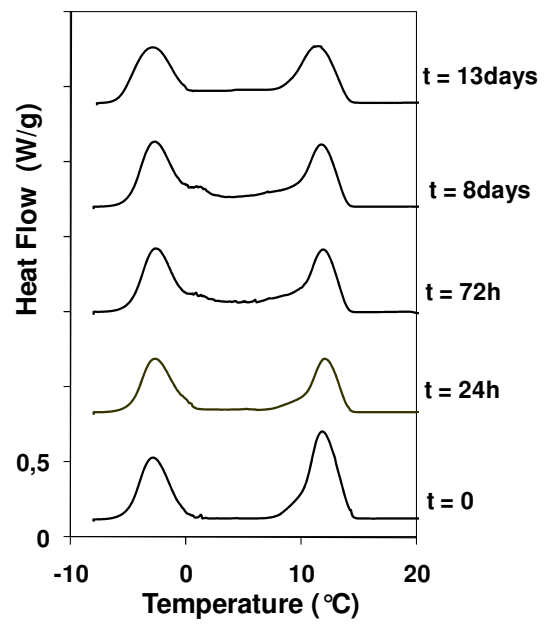

Fig. 18. DSC curves showing the solidification of solid-stabilized O/W mixed emulsion containing $20 \mathrm{wt} \%$ of n-tetradecane droplets and $20 \mathrm{wt} \%$ of n-hexadecane droplets, at successive time intervals

This work shows a preferential mass transfer from the tetradecane to the n-hexadecane droplets in agreement with the literature. Many studies evidenced the importance of the solubility of the oil dispersed phase in water on the direction and the rate of oil exchange through the continuous water phase (Taisne et al., 1996; Binks et al., 1998; 1999). Indeed, it was demonstrated that the Tween 20 surfactant enhances the solubility of the tetradecane rather than the hexadecane (McClement et al., 1995; Weiss et al., 2000). The results show that the characteristic time scale for oil exchange between tetradecane and n-hexadecane droplets kinetics can span a wide range from seconds to several hours in presence of surfactant. The kinectics of composition ripening seems to depend on parameters of emulsion formulation as the surfactant type, the surfactant concentration, and the amount of salt and the presence of solid particles in the aqueous phase. The results show that the rate of oil exchange between droplets is faster when the non-ionic surfactant concentration is higher, in agreement with the literature (McClement et al., 1993c; Binks et al., 1998; 1999). On the contrary, the amount of salt added into the continuous phase slows down the rate of oil transfer as it was evidenced by McClement et al. (McClement et al., 1993c), and the presence of solid particles seems to block the oil exchange (Drelich et al., 2011). These results suggest that oil transfer may enhanced by the excess of surfactant micelles in the continuous phase. Mechanism of micelle transportation and solubilization of the oil through the continuous phase was proposed in the literature (McClement et al., 1992; 1993a; 1993b, 1993c; Binks et al., 1998; 1999; Elwell et al., 2004).

\subsection{Model of kinetics of composition ripening}

The mechanism of composition ripening has to be considered when a composition gradient exists within the emulsion under study. To model the mass transfer, the mixed emulsions are pictured as: two oil phases of different nature compartmented and separated by a plane liquid aqueous membrane or two aqueous phases of different composition compartmented and separated by a plane liquid membrane made of oil (Figure 19). 


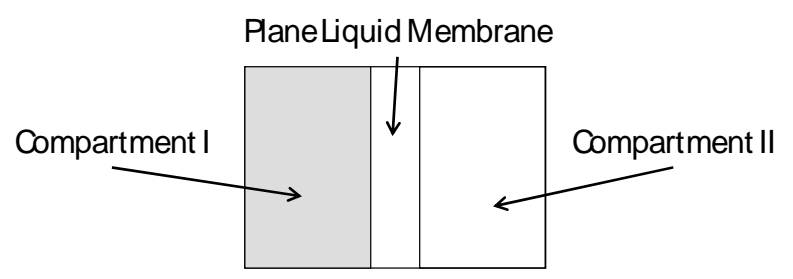

Fig. 19. Picture of mixed emulsion in the model of mass transfer

It has been demonstrated in the presented work and in the literature that the transport of pure water in $\mathrm{W} / \mathrm{O}$ mixed emulsion or the transfer of pure tetradecane in $\mathrm{O} / \mathrm{W}$ mixed emulsion is increased when surfactant making micelles is present as the micelles can incorporated the transferred molecules and facilitate their transport through the continuous media. To quantify the transfer, the flux J is introduced and expressed in terms of chemical potential gradient $\overline{\text { grad }} \mu$ according to the following equation:

$$
\vec{j}=-L \times \overline{\operatorname{grad}} \mu
$$

With $\mathrm{L}$ being the factor related to the transferred material diffusion coefficient and the transferred material concentration in the membrane. By using this model, it has been possible to express the changes of the number of material moles in the compartment I containing pure material, $n_{1}^{I}(t)$ versus time $t$. This number decreases versus time, the material being transferred between two populations of droplets in direction of the decreasing chemical potential. For example, water being transferred from the pure water droplet to the water+solute droplets or tetradecane being transferred from the pure tetradecane droplets to the hexadecane droplets. A mathematical treatment and thermodynamic considerations developed (Clausse et al., 1995a) allow obtaining the following relation:

$$
V^{t}\left[n_{1}^{I}(t=0)^{1 / 3}-n_{1}^{I}(t)^{1 / 3}\right]-\left[n_{1}^{I}(t=0)^{4 / 3}-n_{1}^{I}(t)^{4 / 3}\right]=2 n_{1}^{I I} v_{1}^{2 / 3}\left(V_{0}^{I}\right)^{1 / 3} \frac{L_{D}}{\ddot{d}}
$$

In this equation, $\mathrm{V}$ and $\mathrm{v}$ are the total volume and the molar volume, respectively, and $\mathrm{L}_{\mathrm{p}}$ and $\ddot{d}$ are the permeability coefficient and the mean diameter of the droplets, respectively. Furthermore, $\mathrm{n}_{1}$ and $\mathrm{n}_{2}$ are the moles numbers of water and solute or the moles numbers of tetradecane and hexadecane, respectively. $\mathrm{L}_{\mathrm{p}}$ is a parameter difficult to know as it is linked to unknown parameters such as the width of the equivalent membrane, the water diffusion coefficient or the tetradecane diffusion coefficient and the water concentration or the tetradecane concentration in the membrane. Nevertheless, it is possible from this model to predict the lapse of time necessary to reach equilibrium, when all the pure water molecules has migrated from the pure water droplets to the water+solute droplets, or when the tetradecane molecules has migrated from the pure tetradecane droplets to the diluted hexadecane droplets. This point is reached when $n_{1}^{I}(t)=0$. Similar treatments dealing with water transfer within multiple emulsions have been given in the literature (Clausse et al., 1995b; Potier et al., 1992).

In each studied case, the water transport in $\mathrm{W} / \mathrm{O}$ mixed emulsion and the tetradecane transfer in $\mathrm{O} / \mathrm{W}$ mixed emulsion, experimental results are fairly well fitted by the model proposed. Although this model is not perfect, it gives the main physical parameters to be 
considered and it could be improved by taking account the changes of the characteristics of the emulsion with time due to the transfer, and the emulsifier influence.

\section{Multiple emulsions}

Multiple or double emulsions are systems in which a liquid phase is dispersed into globules which in turn are dispersed into another immiscible liquid phase (Garti \& Lutz, 2004; Benichou et al., 2007). The liquid phase dispersed as microdroplets in the globules is called the internal phase whereas the liquid phase in which are dispersed the globules is called the external phase. Therefore a multiple emulsion contains three liquids phases and are classified as either Water-in-Oil-in-Water (W/O/W) emulsions or Oil-in-Water-in-Oil emulsions (O/W/O) (Pal, 2011; Muschiolik, 2007). The inner dispersed droplets are separated from the external phase by a layer of the globules phase (Garti \& Lutz, 2004).

Multiple emulsions are liquid carriers for entrapped and release of active or reactive molecules in pharmaceutics, cosmetics, food and industrial applications. Nevertheless, $\mathrm{W} / \mathrm{O} / \mathrm{W}$ multiple emulsions are more studied because they have higher potential to become commercial products than $\mathrm{O} / \mathrm{W} / \mathrm{O}$ multiple emulsion (Benichou \& Aserin 2007). For instance, in cosmetics the release of an encapsulated drug inside an aqueous globule of a $\mathrm{W} / \mathrm{O} / \mathrm{W}$ emulsion can be directly liberated by breaking of the globules via mechanical stress (Muguet et al., 2001; Tejado et al., 2001). In pharmaceutics, drugs can be protected by the membrane until it reaches its target and then released by controlled release (Garti \& Lutz, 2004; Hai \& Magdassi, 2004; Tejado et al., 2005). Controlled release can by operated via swelling of the globules (or Ostwald swelling) which consists in an increase in size of the inner dispersed droplets due to a difference of chemical potential on both sides of the membrane leading to a water mass transfer from the external phase to the internal phase (Geiger et al., 1998; Grossiord \& Stambouli, 2007; Lutz et al., 2009). As a consequence, the volume of the oily globules increases and when the resistance of the membrane becomes insufficient, the globule breaks liberating the active compound.

In water waste treatments which also involve $\mathrm{W} / \mathrm{O} / \mathrm{W}$ emulsions, the toxic compound present in the external phase has to diffuse through the membrane to be entrapped in the inner droplets. In such separation processes, selectivity of the membrane is an important parameter (Kentish \& Stevens, 2001; Kumbasar, 2009). Indeed when a compound has to be extracted from a solution containing a variety it is important that only the compound to be extracted diffuses through the membrane. In order to promote selectivity of the membrane, a carrier can be added into the membrane phase (Venkatesan \& Meera Sheriffa Begum, 2009; $\mathrm{Ng}$ et al., 2010). A carrier is a molecule which can form a complex with the toxic compound at the external interface and transport it to the internal phase where the toxic compound will be entrapped (Hasan et al., 2006; Frasca et al., 2009). High selectivity means that the carrier holds a good affinity with the toxic compound in order to exclusively transport it through the membrane (Kaghazchi et al., 2006).

In separation applications, the instability of the multiple emulsions can reduce significantly the efficiency of the process. Indeed, if Ostwald swelling or coalescence of the globules occurs, such mechanisms can lead to the break of the globules. The extracted molecule is then directly released in the external phase which ruins the extraction process (Yan \& Pal, 2001, 2004; Mortaheb et al., 2008).

If $\mathrm{O} / \mathrm{W} / \mathrm{O}$ multiple emulsions have been less extensively studied, they can also finds potential applications in food, cosmetics and controlled delivery drugs (Benichou et al., 
2007; Mishra \& Pandit, 1989; Laugel et al., 1998, 2000; Yu et al., 2003). They are found also in application in separation processes of hydrocarbons (Krishna et al., 1987; Garti \& Kovacs, 1991). In controlled drug delivery applications the challenge consists in the control of the diffusion of the entrapped active molecule (Grossiord et al., 1998). The active matter can diffuse and migrate through the membrane via an osmotic pressure gradient and it can be almost difficult to retain the active molecule inside the inner phase upon prolonged storage, all the more as the emulsifier can form micelles (Benichou et al., 2007). Micelles are capable of solubilizing the active molecule and facilitate the transport of active matter from the internal interface to the external interface.

One can see that developing potential applications of multiple emulsions requires a good understanding of the mass transfer mechanisms but besides measuring kinetics of mass transfer, it is also important to take into account formulation aspects of the emulsion which have also a direct influence on the mass transfer.

$\mathrm{W} / \mathrm{O} / \mathrm{W}$ emulsions entrapping different compounds, urea or $\mathrm{MgSO}_{4}$ have been studied by using the DSC techniques presented in this chapter (Potier et al., 1992; Raynal et al., 1994 Raynal et al, 1993). As case of study we propose to describe the release of tetradecane within an O/W/O multiple emulsion studied by DSC. It is described how to detect the variations of composition of the external oil phases during time as well as the evolution of the emulsion with time. The influence of formulation parameters such as surfactant concentration and mass ratio of the internal phase on the evolution of the emulsion are also discussed.

\subsection{Emulsion preparation}

The tetradecane/Water/hexadecane $\left(\mathrm{O}_{1} / \mathrm{W} / \mathrm{O}_{2}\right)$ multiple emulsions were prepared in a two-step emulsification method (Avendaño-Gomez et al., 2005). Firstly, primary simple emulsions $\mathrm{O}_{1} / \mathrm{W}$ were prepared. Tetradecane was dispersed into an aqueous solution in which was previously dissolved Tween 20. Different concentrations of Tween 20 have been investigated, $2 \mathrm{wt} \%, 4 \mathrm{wt} \%$ and $7 \mathrm{wt} \%$. Tetradecane was then slowly dripped into the aqueous phase under agitation using an Ultra Turrax mixer at a speed of 20,000 rpm. All the $\mathrm{O}_{1} / \mathrm{W}$ emulsions prepared contained a tetradecane/water ratio of $2 / 3$. The primary emulsions were then sonicated during $10 \mathrm{~min}$. The droplet size distribution was measured using Coulter counter technique and the mean size of tetradecane droplets for all primary emulsion was about $5 \mu \mathrm{m}$. In a second step, $19 \mathrm{~g}$ of each primary $\mathrm{O}_{1} / \mathrm{W}$ emulsion was mixed gently in $10.7 \mathrm{~g}$ of the hexadecane external phase containing $1 \mathrm{~g}$ of Abil EM 90 as surfactant and $0.1 \mathrm{~g}$ of decanol as co-surfactant. Each primary emulsion was incorporated slowly in the hexadecane using a Rayneri blender at a speed of $50 \mathrm{rpm}$ and the emulsions were kept under gentle agitation until the duration of the experiments. The globule size of the emulsions was then determined by using a Cannon Microscope and the mean diameter was about $1000 \mu \mathrm{m}$ for the all emulsions prepared.

\subsection{DSC measurements - results and discussions}

Figure 20 presents an example of the evolution of DSC curves obtained for the $\mathrm{O}_{1} / \mathrm{W} / \mathrm{O}_{2}$ multiple emulsions understudied. The DSC curves are characteristic of a multiple emulsion containing $2 \mathrm{wt} \%$ of Tween 20 in the aqueous membrane. On this figure, the initial DSC curve was obtained by submitting the emulsion after 1 minute of its preparation and presents 3 peaks of crystallization. At that time it can be considered that the transfer has not yet started and the three peaks of crystallization corresponds to the crystallization of the 
three phases composing the multiple emulsion. The signal at around $-18^{\circ} \mathrm{C}$ represents the crystallization of the aqueous phase by breakdown of undercooling. This signal is characteristic of bulk water crystallization as it has been described in section 2 . Even if the aqueous phase is dispersed as a multitude of globules their size of $1 \mathrm{~mm}$ is not sufficiently tiny enough to involve nucleation delays like those observed in $\mathrm{W} / \mathrm{O}$ emulsions droplets of a few $\mu \mathrm{m}^{3}$. Therefore the behavior of crystallization of aqueous globule looks like the crystallization of water bulk phase. The exothermic peak at $17^{\circ} \mathrm{C}$ which initial part of the signal is sharp is attributed to the bulk hexadecane crystallization. The hexadecane crystallizes at $17^{\circ} \mathrm{C}$ but with a very little degree of subcooling, the melting temperature of hexadecane being of $18^{\circ} \mathrm{C}$. The third bell shape peak is attributed to the crystallization of the tetradecane dispersed droplets. The temperature is $-12.8^{\circ} \mathrm{C}$ and is given by the apex of the peak which means that nearly $50 \%$ of the droplets are crystallized.

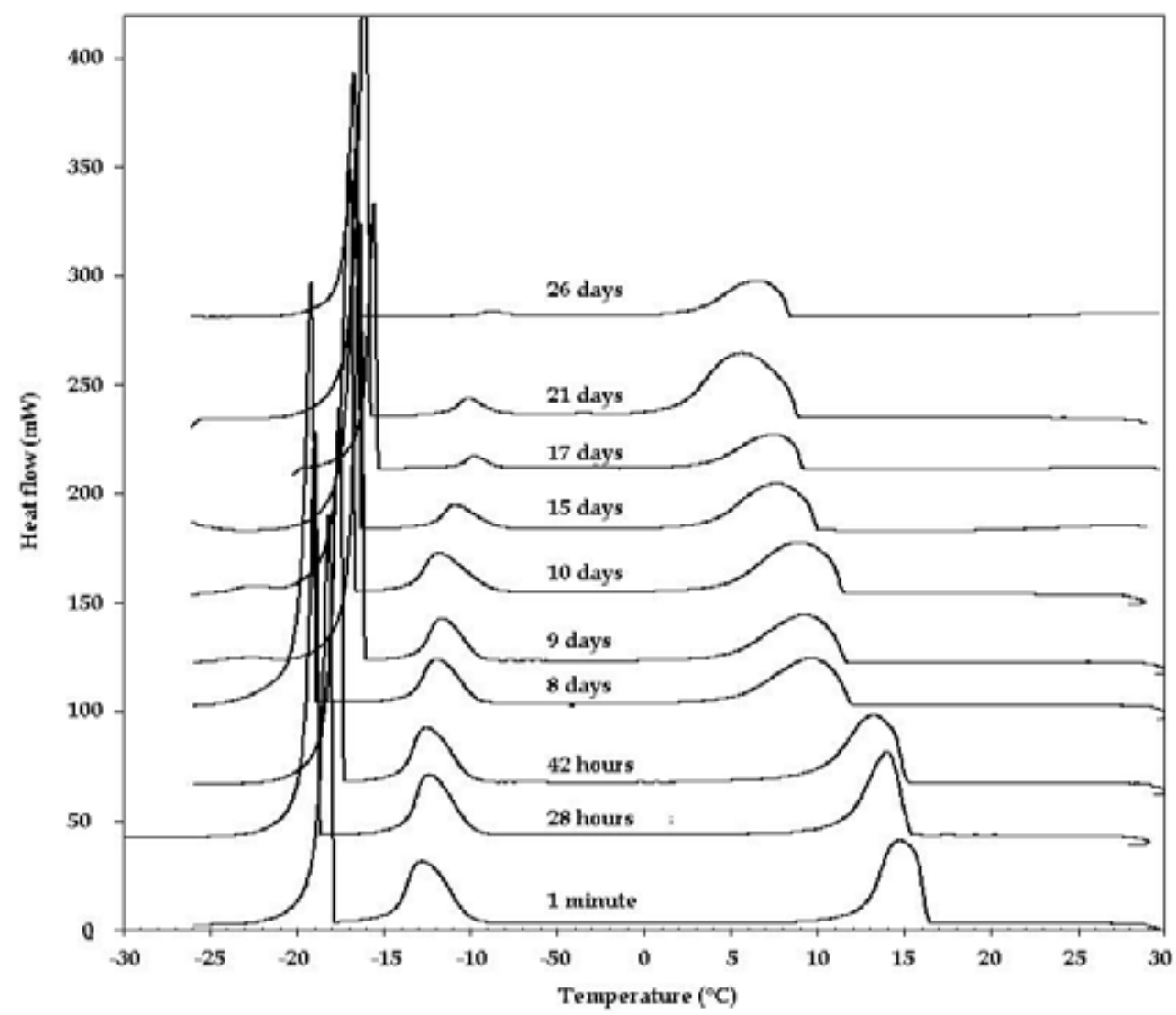

Fig. 20. Evolution of the DSC curves of an $\mathrm{O}_{1} / \mathrm{W} / \mathrm{O}_{2}$ multiple emulsion containing $2 \mathrm{wt} \%$ of Tween 20 in the aqueous membrane

Figure 20 also shows a clearly evolution with time of the crystallization peaks of the internal phase and the external phase. Actually, the crystallization peak of the tetradecane exhibits a 
progressive decrement in intensity whereas the temperature of the crystallization peaks of hexadecane decreases progressively from $17^{\circ} \mathrm{C}$ to $10^{\circ} \mathrm{C}$. From these results it can be deduced that tetradecane releases gradually over time. On the ultimate DSC curve, the crystallization peak of tetradecane disappears which means that the globules are empty and total tetradecane has been transferred in the external phase. Consequently the external phase composition has changed over time from pure hexadecane to a given tetradecanehexadecane composition when the transfer ends, passing through different intermediate compositions.

Using equation 2, it is then possible to determine the percentage $\mathrm{y}$ of tetradecane still entrapped at time $t$. The values of $y$ versus time and obtained for different amounts of Tween $(2,4$ and $7 \%)$ are reported on figure 21 .

The emulsions initially contained the same amount of encapsulated tetradecane and it can be easily observed that the kinetics depend on the amount of Tween 20 contained in the membrane. The higher the concentration of surfactant, the higher is the release of tetradecane. Nevertheless, it must be emphasized that tetradecane is gradually released through the aqueous membrane and that no globule breaking was observed during the lifetime of the multiple emulsion.

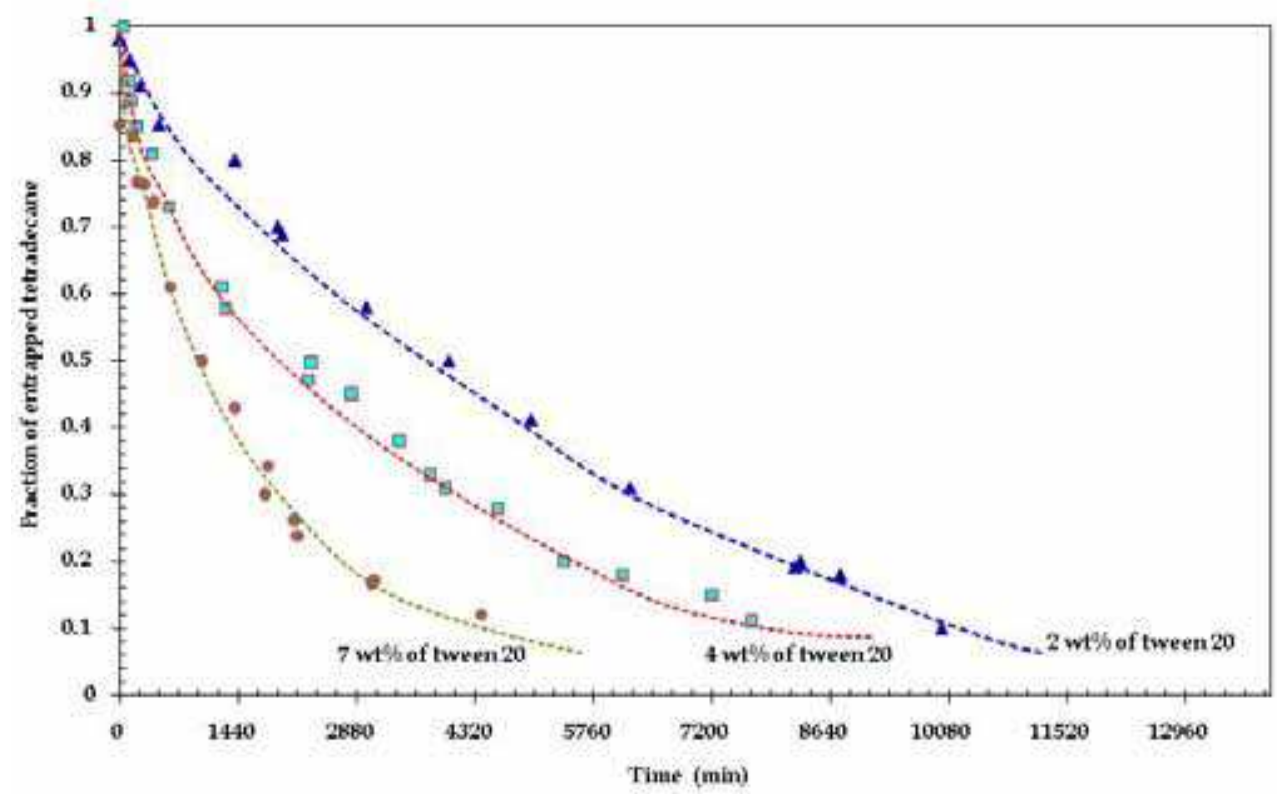

Fig. 21. Evolution of the quantity of tetradecane encapsulated in the globules with time at different concentrations of Tween 20 in the aqueous membranes phase

\subsection{Model of kinetics of tetradecane release}

First a model based on the expressions of the flux of tetradecane versus chemical potential gradient has been used (Avendano, 2002). A solubilisation - diffusion model has been developed and the comparison with the experimental data has shown theoretical release times higher: $50 \%$ released in 4000 minutes (experiment) and 5000 minutes (model). 
Therefore an improved model using the shrinking core model commonly applied to heterogeneous reactions (Stambouli et al., 2007) has been developed. The model has been modified and applied to the multiple emulsions under studied. Owing to the fact that the structure of multiple emulsions is complex and in order to simplify the mathematical treatment of the model, it has been assumed that the internal droplets of tetradecane form only one virtual drop encapsulated in an aqueous spherical shell which represents the membrane. The shrinking model and the typical concentration profile for diffusive transport of tetradecane through the membrane are described in figure 22. For clarity reasons let us define first of all, the notations used in the description of the kinetics model: $C_{I}$ represents the pure tetradecane into the internal virtual drop. $\mathrm{C}_{\mathrm{II}}$, is the tetradecane concentration in the external phase (tetradecane + hexadecane). $C_{I}^{\prime}$ is the tetradecane concentration at the interface in the aqueous phase at interface I. $C_{\mathrm{II}}^{\prime}$ is the tetradecane concentration in the aqueous phase at the interface II. $\mathrm{C}^{\prime}(\mathrm{r})$ is the tetradecane concentration in the aqueous phase at radius $r . r_{I}$ and $r_{I I}$ are the radius of the internal virtual tetradecane drop and the radius of the aqueous globule respectively.

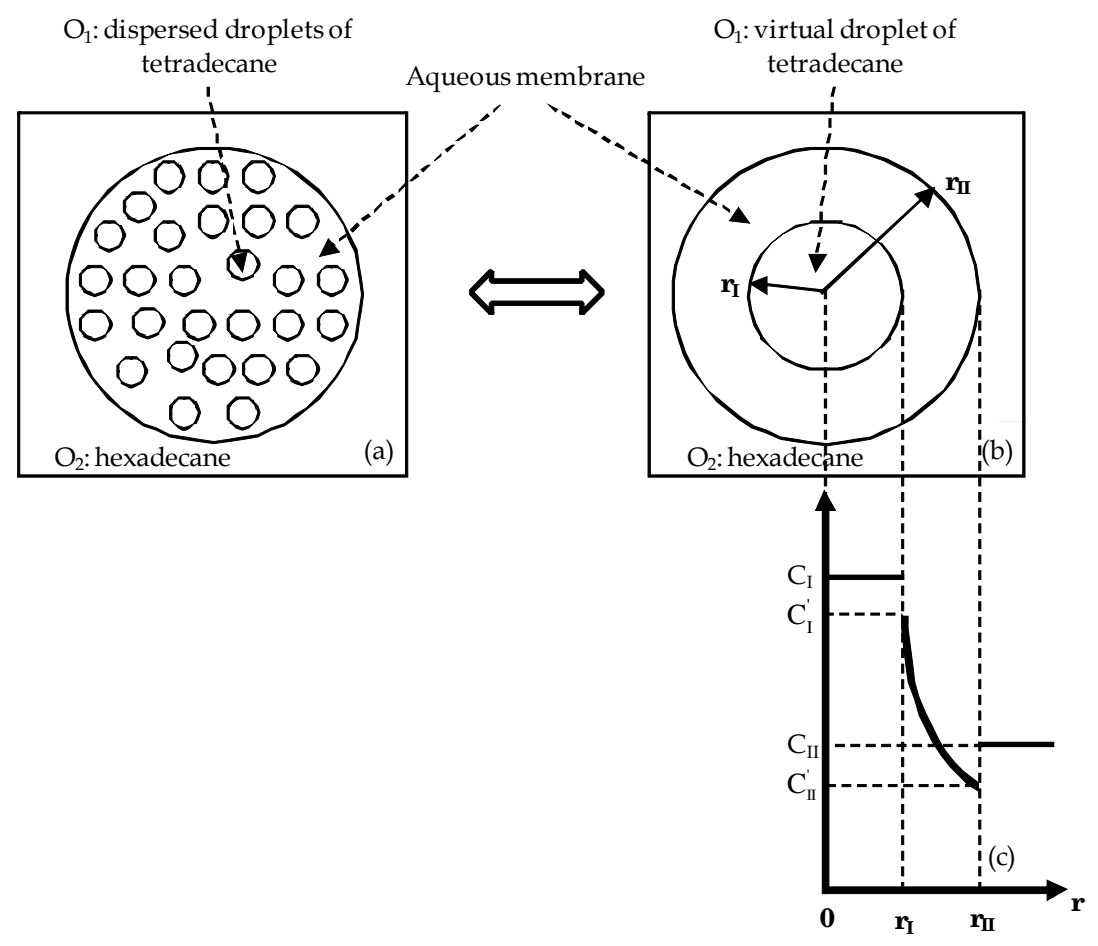

Fig. 22. (a) Schematic representation of the tetradecane/water/oil emulsion. (b) A multiple globule containing a virtual drop of tetradecane surrounding by a spherical aqueous membrane shell. (c) Profile of tetradecane concentration in the emulsion

Two partition coefficients can be defined as the ratios between the concentration of tetradecane concentration in the aqueous membrane phase and the oily phases I and II considering that equilibrium is assumed at both water/oil interfaces I and II. 


$$
\begin{gathered}
K_{1}=\frac{C_{\mathrm{I}}^{\prime}}{C_{\mathrm{I}}} \\
K_{2}=\frac{C_{\mathrm{II}}^{\prime}}{C_{\mathrm{II}}}
\end{gathered}
$$

For simplification, it is considered that the internal dispersed droplets of tetradecane are immobile inside the aqueous globules and are able to release tetradecane in the external phase through the membrane. Therefore, it is assumed that the release of tetradecane occurs via a pure molecular diffusion or pure micellar diffusion.

The expression of the tetradecane flow through the aqueous spherical membrane shell of radius $r$ is expressed as equation (11) where $D_{e}$ is the effective diffusion coefficient of tetradecane in the aqueous membrane phase.

$$
\mathcal{J}(r)=-4 \Pi r^{2} D_{e}\left(\frac{d C^{\prime}}{d r}\right)
$$

From mass balance equations and integration between $r=r_{1}$ and $r=r_{2}$ assuming that the volume of the aqueous membrane does not vary during the tetradecane release, the time $t$ of release can be expressed by the following equation

$$
t=\frac{\rho_{T}\left(r_{\mathrm{I}}^{0}\right)^{2}}{2 D_{e} \Delta C^{*}}\left[\left(Z_{0}-x\right)^{\frac{2}{3}}-(1-x)^{\frac{2}{3}}+1-Z_{0}^{\frac{2}{3}}\right]
$$

where $\Delta C^{*}=C_{I}^{\prime}-C_{I I}^{\prime} ; \rho_{\mathrm{T}}$ and $\mathrm{V}_{\mathrm{T}}$ are respectively the density of tetradecane and the volume of the virtual tetradecane phase I; $Z_{0}=\left(\frac{r_{I}^{0}}{r_{I}^{0}}\right)^{3}, y=\frac{r_{I}}{r_{I}^{0}}$ where $r_{I}^{0}$ is the initial radius of the virtual tetradecane droplet.

If we considered the time $t_{1}$ at which the internal tetradecane phase is completely release, $\left(r_{1}=0\right.$ and $\left.x=1\right)$, then $t_{1}$ is expressed as

$$
t_{1}=\frac{\rho_{T}\left(r_{I}^{0}\right)}{2 D_{e} \Delta C^{*}}\left[\left(Z_{0}-1\right)^{\frac{2}{3}}+1-Z_{0}^{\frac{2}{3}}\right]
$$

Finally it is possible to write the time $t$ of release in the equivalent following form as

$$
t=\frac{t_{1}}{\left[\left(Z_{0}-1\right)^{\frac{2}{3}}+1-Z_{0}^{\frac{2}{3}}\right.}\left[\left(Z_{0}-x\right)^{\frac{2}{3}}-(1-x)^{\frac{2}{3}}+1-Z_{0}^{\frac{2}{3}}\right]
$$

Taking into account the value of $Z_{0}$ from equation 15 , it was possible by using equation (14) where $t_{1}$ is the fitting parameter and the least-squares method to obtain the best fitting of the experimental data relating to the tetradecane release $x$ versus time. 


$$
Z_{0}=\left(\frac{r_{I I}^{0}}{r_{I}^{0}}\right)^{3}=\frac{0.282+0.326}{0.282}
$$

Where 0.282 and 0.326 are the volume fractions of the tetradecane phase and the membrane aqueous phase in the multiples emulsions respectively.

Figure 23 presents the experimental and the model results obtained from a multiple emulsion containing $2 \mathrm{wt} \%$ of Tween 20 in the membrane phase. The model fits well the experimental data. It is worth noting that the model also fits the experimental data for the multiple emulsions containing 4 and $7 \mathrm{wt} \%$ of Tween 20 in the aqueous membrane phase. The time $t_{1}$ of complete release of tetradecane has been derived from the three formulations and it was obtained, $t_{1}=875 h, t_{1}=451 h$ and $t_{1}=318 h$ for 2,4 and $7 \mathrm{wt} \%$ of Tween 20 respectively. In the model, the values of $\frac{D_{e} \Delta C^{*}}{\rho_{T}}$ were fitted using equation 12 using $r_{I}^{0}=0.387 \mathrm{~mm}$ calculated from $\mathrm{Z}_{\mathrm{o}}\left(r_{I I}^{0}=1 \mathrm{~mm}\right)$. The values of the effective diffusion coefficient obtained were compared to those of literature (Mandal et al, 1985) and a difference was observed. However, the order of magnitude of the effective diffusion coefficient is in a good agreement with the literature data. Therefore, it can be concluded that the tetradecane release is strongly dependent from the Tween 20 concentration and occurs by a micellar transport mechanism. The difference observed between the diffusion coefficients from the model and literature may be due to the simplifications made for developing the model. A more accurate model can be proposed but new empirical parameters are needed.

\section{Tetradecane Release $($ Tween $=2 \%)$}

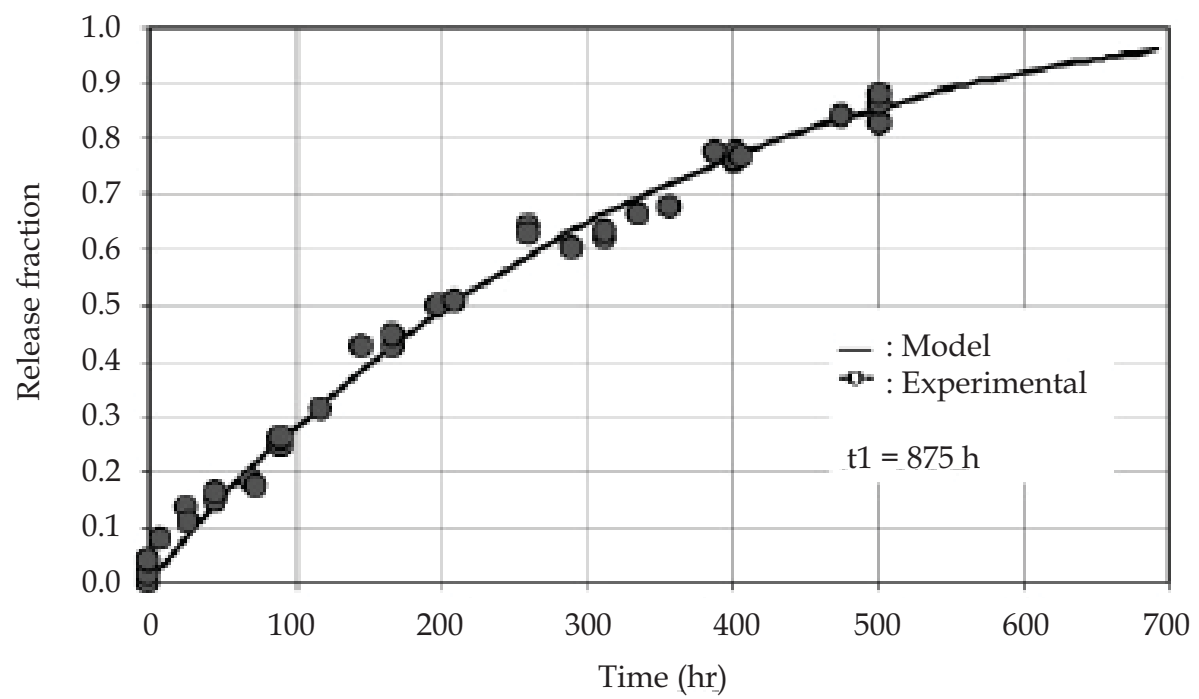

Fig. 23. Tetradecane release obtained from the model and compared to the experimental data. Example of an emulsion containing $2 \mathrm{wt} \%$ of Tween 20 in the aqueous membrane 


\section{Conclusion}

Mass transfers occurring within different kinds of emulsions, simple, mixed and multiple, have been described in this chapter. Almost of the examples given are dealing with mass transfer occurring at ambient temperature between phases of different composition. Focus has been made about the results obtained by submitting time to time an emulsion sample to a cooling and heating cycle during which freezing and melting of the phases concerned by the mass transfer are registered through the energies involved in the liquid - solid transition thanks to a differential scanning calorimeter. The amount of the transferred mass is deduced either from the freezing or melting of the pure material droplets A or from the calibration curve that gives the freezing temperature of the droplets made of $A+B$, versus the composition. This DSC technique appears to be suitable to study this kind of phenomenon as far it permits to follow the transfer and furthermore to get the kinetic of the transfer. Doing so a model of the transfer can be set up and the mechanisms involved can be described. It appears that the mechanism to be considered is a solution diffusion transfer facilated by micelles that entrapped the compound to be transferred. Therefore a control release can be set up through the formulation of the emulsion. Another type of mass transfer has been described that induces solid ripening as the result of the mass transfer. The case of hydrate formation has been given as an example. The mass transfer due to the diffusion of a material in the oil phase of a $\mathrm{W} / \mathrm{O}$ emulsion, induces the formation of a solid compound, namely an hydrate, when this compound chemically reacts with water of the dispersed water. Here as well, the DSC technique appears to be suitable but due to overlapping of transitions dealing with water and hydrate a complementary technique is needed. That shows the limit of the DSC technique that needs net liquid-solid transitions and a reduced overlapping of the transitions. To conclude these studies show the great advantage to use emulsions for having mass transfer in a rather short time due to the total high surface area of exchange and the presence of micelles. Therefore, these systems can be considered to set up separation processes, the emulsions being seen as liquid membranes systems or as mini reactors for getting chemical reactions between compounds. Nevertheless a control of the formulation of the emulsions in order to get kinetically stable emulsions at least during the process involved is needed.

\section{References}

Ariyaprakai, S. \& Dungan, S. R. (2010). Influence of surfactant structure on the contribution of micelles to Ostwald ripening in oil-in-water emulsions. eburnal of Colloid and Interface Science, Vol. 343, No. 1, (March 2010) pp. 102-108 ISSN 0021-9797

Avendano-Gomez, J.; Grossiord, J.L. \& Clausse, D. (2000). Composition ripening in o/w emulsions. Entropie, Vol. 36, No. 224-25, (September 1999) pp. 110-116 ISSN 00139084

Avendaño-Gomez, J. (2002).Etude par calorimétrie du mûrissement de composition dans une émulsion mixte $\mathrm{H}_{1}-\mathrm{H}_{2}$ /eau et une émulsion multiple $\mathrm{H}_{1} /$ eau/ $\mathrm{H}_{2}$. Thèse de Doctorat de l'Université de Technologie de Compiègne, France 
Avendaño-Gomez, J. R.; Grossiord, J.L. \& Clausse, D. (2005). Study of mass transfer in oilwater-oil multiple emulsion by differential scanning calorimetry. eburnal of Colloid and Interface Science, Vol. 290, No. 2, (October 2005) pp. 533-545 ISSN 0021-9797

Benichou, A.; Aserin, A. \& Garti, N. (2007). O/W/O double emulsions stabilized with WPIpolysaccharide conjugates. Colloids and surfaces A: Physicochem. Eng. Aspects, Vol. 297, No. 1-3, (April 2007) pp. 211-220 ISSN 0927-7757

Benichou, A. \& Aserin, A. (2007). Recent developments in O/W/O multiple emulsions, In: Multiple Emulsion: Technology and Applications, A. Aserin, pp. (165-208), John Wiley and Sons Inc. ISBN 978-0-470-17093-9, Hoboken, USA

Binks, B. P.; Clint, J.H.; Fletcher, P.D.I. \& Rippon, S. (1998). Kinetics of swelling of oil-inwater emulsions. Langmuir, Vol. 14, No. 19, (September 1998) pp. 5402-5411 ISSN 0743-7463

Binks, B. P.; Clint, J.H.; Fletcher, P.D.I. \& Rippon, S. (1999). Kinetics of swelling of oil-inwater emulsions stabilized by different surfactants. Langmuir, Vol. 15, No. 13 (June 1999) pp. 4495-4501 ISSN 0743-7463.

Capek, I. (2004). Degradation of kinetically-stable o/w emulsions. Advances in Colloid and Interface Science, Vol. 107, No. 2-3, (March 2004) pp. 125-155 ISSN 0001-8686

Clausse, D. (1985). Caractérisation des propriétés thermodynamiques d'une émulsion. Détermination de la température et de l'enthalpie de changement d'état de la phase dispersée. Revue Générale de Thermique, Vol. 279, pp. 263-268 ISSN 0035-3159

Clausse, D.; Pezron, I. \& Gauthier, A. (1995a). Water transfer in mixed water-in-oil emulsions studied by differential scanning calorimetry. Fluid Phase Equilibria, Vol. 110, No. 1-2, (September 1995) pp.137-150 ISSN 0378-3812

Clausse, D.; Pezron, I. \& Raynal, S. (1995b). Water transfer within multiple W/O/W Emulsions at a fixed subambiant temperature. Cryo-Letters, Vol. 16, No. 4, (JulyAugust 1995), pp. 219-230 ISSN 0143-2044

Clausse, D.; Pezron, I. \& Behaeghel, A. (1999a). Water transfer between water and water $+\mathrm{NaCl}$ droplets in emulsions, eburnal of Dispersion Science and Technology, Vol. 20, No. 1-2, (1999a) pp. 315-326 ISSN 0193-2691

Clausse, D.; Pezron, I. \& Komunjer, L. (1999b). Stability of W/O and W/O/W emulsions as a result of partial solidification. Colloids and Surface A: Physicochemical and engineering Aspects, Vol. 152, No. 1-2, (July 1999) pp. 23-29 ISSN 0927-7757

Clausse, D.; Fouconnier, B. \& Avendaño-Gomez, J. R. (2002b). Ripening phenomena in Emulsions - A calorimetry investigation. eburnal of Dispersion Science and Technology, Vol. 23, No. 1-3, pp. 379-391 ISSN 0193-2691

Clausse, D.; Gomez, F.; Pezron, I.; Komunjer, L. \& Dalmazzone, C. (2005). Morphology characterization of emulsions by differential scanning calorimetry. Advances in Colloid and Interface Science, Vol. 117, No. 1-3, (December 2005) pp. 59-74 ISSN 00018686

Clausse, D.; Pezron, I.; Gomez, F.; Dalmazzone, C.; Sacca, L. \& Drelich, A. (2008). Differential Scanning Calorimetry as a tool for following emulsion evolution in microgravity conditions from the MAP-Project FASES. eburnal of the elopan Society of Microgravity Application, Vol. 25, No. 3, pp. 227-230 
Colinart, P.; Delepine, S.; Trouve, G. \& Renon, H. (1984). Water transfer in emulsified liquid membrane process. eburnal of membrane Science, Vol. 20, No. (August 1984) pp. 167187 ISSN 0376-7388

Dalmazzone, D.; Kharrat, M.; Lachet, V.; Fouconnier, B. \& Clausse, D. (2002). DSC and PVT measurements of methane and trichlorofluoromethane hydrate dissociation equilibria in highly concentrated calcium chloride solutions and water-in-oil emulsions. eburnal of thermal Analysis and Calorimetry, Vol. 70, (February 2002) pp. 493-505 ISSN 1418-2874

Dalmazzone, D.; Hamed, N. \& Dalmazzone, D. (2009). DSC measurements and modelling of the kinetics of methane hydrate formation in water-in-oil emulsion. Chemical Engineering Science, Vol. 64, No. 9, (May 2009) pp. 2020-2026 ISSN 0009-2509

Davies, S. R.; Hester, K. C.; Lachance, J. W.; Koh, C. A. \& Sloan, E. D. (2009). Studies of hydrate nucleation with high pressure differential scanning calorimetry. Chemical Engineering Science, Vol. 64, No. 2, (January 2009) pp. 370-375 ISSN 0009-2509

Drelich, A. (2009). Emulsions formulées avec des particules de silice: caractérisation, stabilité, transfert de matière. Thèse de Doctorat de l'Université de Technologie de Compiègne, France

Drelich, A.; Gomez, F.; Grossiord, J. L.; Clausse, D. \& Pezron, I. (2011). to be published.

Elwell, M.W.; Roberts, R.F. \& Coupland, J.N. (2004). Effect of homogenization and surfactant type on the exchange of oil between emulsion droplets. Food Hydrocolloids, Vol. 18, No. 3, (May 2004) pp. 413-418 ISSN 0268-005X

Fouconnier, B.; Legrand, V.; Komunjer, L.; Clausse, D.; Bergfoldt, L. \& Sjöblom, J. (1999). Formation of trichlorofluoromethane hydrate in w/o emulsions studied by differential scanning calorimetry. Progress in colloid \& polymer science, vol. 112, pp. 105-108 ISSN 0340-255X

Fouconnier, B.; Manissol, Y.; Dalmazzone, D. \& Clausse, D. (2002). Study of trichlorofluoromethane hydrate formation in W/O emulsions : dissociation energy and equilibrium with salt + water solutions. Entropie, Vol. 38 No. 239-240, (August 2002) pp. 72-77 ISSN 0013-9084

Fouconnier, B.; Komunjer, L.; Ollivon, M.; Lesieur, P.; Keller, G. \& Clausse, D. (2006). Study of $\mathrm{CCl}_{3} \mathrm{~F}$ hydrate formation and dissociation in $\mathrm{W} / \mathrm{O}$ emulsion by differential scanning calorimetry and X-ray diffraction. Fluid Phase Equilibria, Vol. 250, No. 1-2, (December 2006) pp. 76-82 ISSN 0378-3812

Frasca, S.; Couvreur, P.; Seiller, M.; Pareau, D.; Lacour, B.; Stambouli, M. \& Grossiord, J. L. (2009). Paraquat detoxication with multiple emulsions. International eburnal of Pharmaceutics, Vol. 380, No.1-2, (October 2009) pp 142-146 ISSN 0378-5173

Grossiord, J. L. \& Stambouli, M. (2007). Potentialities of W/O/W Multiple Emulsions in Drug Delivery and Detoxification, In: Multiple Emulsion: Technology and Applications, A. Aserin, pp. (209-234), John Wiley and Sons Inc. ISBN 978-0-470-17093-9, Hoboken, USA

Garti, N. \& Kovacs, A. (1991). Facilitated emulsion liquid membrane separation of complex hydrocarbon mixtures. eburnal of Membrane Science, Vol. 56, No. 3, (March 1991) pp. 239-246 ISSN 0376-7388 
Garti, N. \& Lutz, R. (2004). Recent progress in double emulsion, In: Emulsions: Structure Stability and Interactions, D. N. Petsev, pp. (557-667), Elsevier. ISBN 0-12-088499-2, Oxford, UK

Geiger, S.; Tokgoz, S.; Fructus, A.; Jager-Lezer, N.; Seiller, M.; Lacombe, C. \& Grossiord, J. L. (1998). Kinetics of swelling-breakdown of a W/O/W multiple emulsion: possible mechanisms for the lipophilic surfactant effect. eburnal of Controlled Release, Vol. 52, No. 1-2, (March 1998) pp. 99-107 ISSN 0168-3659

Grossiord, J. L.; Seiller, M. \& Silva-Cunha, A. (1998). Obtaining multiple emulsions, In : Multiple emulsions: structure, properties and applications, M. Seiller, J. L. Grossiord, pp. 57-80, Edition de santé. ISBN 2-86411-119-5, Paris, France.

Hai, M. \& Magdassi, S. (2004). Investigation on the release of fluorescent markers from $\mathrm{w} / \mathrm{o} / \mathrm{w}$ emulsions by fluorescence-activated cell sorter. eburnal of Controlled Release, Vol. 96, No. 3-18, (May 2004) pp. 393-402 ISSN 0168-3659

Hasan, M. A.; Selim, Y. T. \& Mohamed, K. M. (2006). Removal of chromium from aqueous waste solution using liquid emulsion membrane. eburnal of Hazardous Materials, Vol. 168, No. 2-3, (September 2009) pp. 1537-1541 ISSN 0304-3894

Jakobsen, T.; Sjöblom, J. \& Ruoff, P. (1996). Kinetics of gas hydrate formation in W/Oemulsions the model system trichlorofluoromethane/water/non-ionic surfactant studied by means of dielectric spectroscopy. Colloids and Surfaces A: Physicochemical and Engineering Aspects, Vol. 112, No. 1, (July 1996) pp. 73-84 ISSN 0927-7757

Jiao, J. \& Burgess, D. J. (2003). Ostwald ripening of water-in-hydrocarbon emulsions. eburnal of Colloid and Interface Science, Vol. 264, No. 2, (August 2003) pp. 509-516 ISSN 00219797

Kaghazchi, T.; Kargari, A.; Yegani, R. \& Zare, A. (2006). Emulsion liquid membrane pertraction of L-lysine from dilute aqueous solutions by D2EHPA mobile carrier. Desalination, Vol. 190, No.1-3, (April 2006) pp. 161-171 ISSN 0011-9164

Kentish, S. E. \& Stevens, G. W. (2001). Innovations in separation technology for the recycling and re-use of liquid waste streams. Chemical Engineering eburnal, Vol. 84, No. 2, (October 2001) pp. 149-159 ISSN 1385-8947

Kharrat, M. \& Dalmazzone, D. (2003). Experimental determination of stability conditions of methane hydrate in aqueous calcium chloride solutions using high pressure differential scanning calorimetry. eburnal of Chemical Thermodynamics, Vol. 35, No. 9, (September 2003) pp. 1489-1505 ISSN 0021-9614

Koh, C. A.; Westacott, R.E.; Zhang, W.; Hirachand, K.; Creek, J. L. \& Soper, A. K. (2002). Mechanisms of gas formation and inhibition. Fluid Phase Equilibria, Vol. 194-197, (March 2002) pp. 143-151 ISSN 0378-3812

Krishna, R.; Goswami, A. N. \& Sharma, A. (1987). Effect of emulsion breakage on selectivity in the separation of hydrocarbon mixtures using aqueous surfactant membranes. eburnal of Membrane Science, Vol. 34, No. 2, (1987) pp. 141-154 ISSN 0376-7388

Kumbasar, R. A. (2009). Extraction and concentration study of cadmium from zinc plant leach solutions by emulsion liquid membrane using trioctylamine as extractant. Hydrometallurgy,Vol. 95, No.3-4, (February 2009) pp. 290-296 ISSN 0304-386X 
Lachance, J. W.; Dendy Sloan, E. \& Koh C. A. (2008). Effect of hydrate formation/ dissociation on emulsion stability using DSC and visual techniques. Chemical Engineering Science, Vol. 63, No. 15, (August 2008) pp. 3942-3947 ISSN 0009-2509

Laugel, C.; Baillet, A.; Youenang Piemi, M. P.; Marty, J. P. \& Ferrier, D. (1998). Oil-water-oil multiple emulsion for prolonged delivery of hydrocortisone after topical application: comparison with simple emulsion. International eburnal of Pharmaceutics, Vol. 160, No.1, (January 1998) pp. 109-117 ISSN 0378-5173

Laugel, C.; Rafidison, P.; Potard, G.; Aguadisch, L. \& Baillet, A. (2000). Modulated release of triterpenic compounds from a $\mathrm{O} / \mathrm{W} / \mathrm{O}$ multiple emulsion formulated with dimethicones: infrared spectrophotometric and differential calorimetric approaches. eburnal of Controlled Release, Vol. 63, No.1-2, (January 2000) pp. 7-17 ISSN 0168-3659

Le Parlouër, P.; Dalmazzone, C.; Herzhaft, B.; Rousseau, L. \& Mathonat, C. (2004). Characterisation of gas hydrate formation using a new high-pressure micro-DSC. cburnal of Thermal Analysis and Calorimetry, Vol. 78, No. 1, (2004) pp. 165-172 ISSN 1388-6150

Li, N. N. (1968). Membrane separation process. US Patent 3410794

Lutz, R.; Aserin, A.; Wicker, L. \& Garti, N. (2009). Release of electrolytes from W/O/W double emulsions stabilized by a soluble complex of modified pectin and whey protein isolate. Colloids and Surfaces B: Biointerfaces, Vol. 74, No. 1, (November 2009) pp. 178-185 ISSN 0927-7765

Mandal, A. B.; Gupta, S. \& Moulik S. P. (1985). Characterization of Tween-20 and Tween-80 micelles in aqueous medium from transport studies. Indian eburnal of chemistry, Vol. 24A, No. 8, pp. 670-674 (1985) ISSN 0376-4710

McClements, D. J.; Dungan, S. R.; German, J. B. \& Kinsella, J. E. (1992). Oil exchange between oil-in-water emulsion droplets stabilised with a non-ionic surfactant. Food Hydrocolloids, Vol. 6, No. 5 (November 1992) pp. 415-422 ISSN 0268-005X

McClements, D. J.; Dungan, S. R.; German, J. B. \& Kinsella, J. E. (1993a). Evidence of Oil Exchange between Oil-in-Water Emulsion Droplets Stabilized by Milk Proteins. eburnal of Colloid and Interface Science, Vol. 156, No. 2 (March 1993) pp. 425-429 ISSN 0021-9797

McClements, D. J.; Dungan, S. R.; German, J. B. \& Kinsella, J. E. (1993b). Factors which affect oil exchange between oil-in-water emulsion droplets stabilized by whey protein isolate: protein concentration, droplet size and ethanol. Colloids and Surfaces A: Physicochemical and Engineering Aspects, Vol. 81, No. 13 (December 1993) pp. 203-210 ISSN 0927-7757

McClements, D. J. \& Dungan, S. R. (1993c). Factors that affect the rate of oil exchange between oil-in-water emulsion droplets stabilized by a non-ionic surfactant: droplet size, surfactant concentration, and ionic strength. eburnal of Physical Chemistry, Vol. 97, No. 28 (July 1993) pp. 7304-7308 ISSN 0022-3654

Mishra, B. \& Pandit, J. R. (1989). Prolonged release of pentazocine from multiple O/W/O emulsions. Drug Development Industrial Pharmacy, Vol. 15, No. 8, pp. 1217-1230 (1989) ISSN: 0363-9045 
Mortaheb, H. R.; Aminia, M. H.; Sadeghiana, F.; Mokhtarania, B. \& Daneshyara, H. (2008). Study on a new surfactant for removal of phenol from wastewater by emulsion liquid membrane. eburnal of Hazardous Materials, Vol. 160, No. 2-3, (December 2008) pp. 582-588 ISSN 0304-3894

Muschiolik, G.; (2007). Multiple emulsions for food use. Current Opinion in Colloid \& Interface Science, Vol. 12, (August 2007) pp. 213-220 ISSN 1359-0294

Muguet, V.; Seiller, M.; Barratt, G.; Ozer, O.; Marty, J. P. \& Grossiord, J. L. (2001). Formulation of shear rate sensitive multiple emulsions. eburnal of control release, Vol. 70, No. 1-2 (January 2001) pp. 37-49 ISSN 0168-3659

Ng, Y. S.; Jayakumar, N. S. \& Hashim, M. A. (2010). Performance evaluation of organic emulsion liquid membrane on phenol removal. eburnal of Hazardous Materials, Vol. 184, No.1-3, (December 2010) pp. 255-260 ISSN 0304-3894

Noble, R. D. \& Stern, A. A. (1995). Membrane separation technology: Principle and application, In: , R. D. Noble \& A. A. Stern, Elsevier Science ISBN 044481633X, Amsterdam, The Netherlands

Tedajo, G. M.; Seiller, M.; Prognon, P. \& Grossiord, J. L. (2001). pH compartmented W/O/W multiple emulsion: a diffusion study. eburnal of control release, Vol. 75, No. 1-2 (July 2001) pp. 45-53 ISSN 0168-3659

Tedajo, G. M. et al. (2005). Release of antiseptics from the aqueous compartments of a W/O/W multiple emulsion. International eburnal of Pharmaceutics, Vol. 288, No. 1, 6 (January 2005) pp. 63-72 ISSN 0378-5173

Venkatesan, S. \& Meera Sheriffa Begum, K.M. (2009). Emulsion liquid membrane pertraction of benzimidazole using a room temperature ionic liquid (RTIL) carrier. Chemical Engineering eburnal, Vol. 148, No. 2-3, (May 2009) pp. 254-262 ISSN 1385-8947

Yan, J. \& Pal, R. (2001). Osmotic swelling behavior of globules of W/O/W emulsion liquid membranes. eburnal of Membrane Science, Vol. 190, No.1, (August 2001) pp. 79-91 ISSN 0376-7388

Yan, J. \& Pal, R. (2004). Effects of aqueous-phase acidity and salinity on isotonic swelling of $\mathrm{W} / \mathrm{O} / \mathrm{W}$ emulsion liquid membranes under agitation conditions. eburnal of Membrane Science, Vol. 244, No.1-2, (November 2004) pp. 193-203 ISSN 0376-7388

Pal, R. (2011). Rheology of simple multiple emulsions. Current Opinion in Colloid \& Interface Science, Vol. 16, No. 1, (February 2011) pp. 41-60 ISSN 1359-0294

Potier, L.; Raynal, S.; Seiller, M.; Grossiord, J.L. \& Clausse, D. (1992). Study state transitions within multiple $\mathrm{W} / \mathrm{O} / \mathrm{W}$ emulsions using calorimetry (DSC). Thermochimica Acta, Vol. 204, No. 1, (July 1992) pp. 145-155 ISSN 0040-6031

Potier, L. (1993). Etude par calorimétrie des changements d'état dans une émulsion multiple E/H/E : Application aus transferts de solvant entre deux phases aqueuses. Thèse de Doctorat de l'Université de Technologie de Compiègne, France

Raynal, S.; Potier, L.; Garcia, S. \& Clausse, D. (1992). Etude par analyse Enthalpique Différentielle de la surfusion et de la sursaturation de solutions aqueuses d'urée. Proceeding ACAT, Vol. 23

Sacca, L.; Drelich, A.; Gomez, F.; Pezron, I. \& Clausse, D. (2008). Composition Ripening in Mixed Water-in-oil Emulsions Stabilized with Solids Particles. eburnal of Dispersion Science and Technology, Vol. 29, N 7, (2008) pp. 948-952 ISSN 0193-2691 
Stambouli, M.; Avendano-Gomez, J. R.; Pezron, I.; Pareau, D.; Clausse, D. \& Grossiord, J. L. (2007). Modelization of the release from a tetradecane/water/hexadecane multiple emulsion: Evidence of significant micellar diffusion. Langmuir, Vol. 23, No. 3, (January 2007) pp. 1052-1056 ISSN 0743-7463

Taisne, L.; Walstra, P. \& Cabane, B. (1996). Transfert of oil between emulsion droplets. eburnal of Colloid and Interface Science, Vol. 184, No. 2 (December 1996) pp. 378-390 ISSN 0021-9797

Weiss, J.; Cancelliere, C. \& McClements, D.J. (2000). Mass Transport Phenomena in Oil-inWater Emulsions Containing Surfactant Micelles: Ostwald Ripening. Langmuir, Vol. 16 No. 17, (August 2000) pp. 6833-6838 ISSN 0743-7463

Yu, S. C.; Bochot, A.; Le Bas, G.; Chéron, M.; Mahuteau, J.; Grossiord, J. L.; Seiller, M. \& Duchêne, D. (2009). Effect of camphor/cyclodextrin complexation on the stability of O/W/O multiple emulsion. International eburnal of Pharmaceutics, Vol. 261, No. 1-2, (August 2003) pp. 1-8 ISSN 0378-5173 


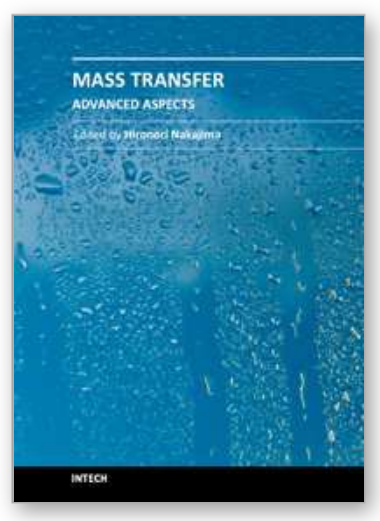

\author{
Mass Transfer - Advanced Aspects \\ Edited by Dr. Hironori Nakajima
}

ISBN 978-953-307-636-2

Hard cover, 824 pages

Publisher InTech

Published online 07, July, 2011

Published in print edition July, 2011

Our knowledge of mass transfer processes has been extended and applied to various fields of science and engineering including industrial and manufacturing processes in recent years. Since mass transfer is a primordial phenomenon, it plays a key role in the scientific researches and fields of mechanical, energy, environmental, materials, bio, and chemical engineering. In this book, energetic authors provide present advances in scientific findings and technologies, and develop new theoretical models concerning mass transfer. This book brings valuable references for researchers and engineers working in the variety of mass transfer sciences and related fields. Since the constitutive topics cover the advances in broad research areas, the topics will be mutually stimulus and informative to the researchers and engineers in different areas.

\title{
How to reference
}

In order to correctly reference this scholarly work, feel free to copy and paste the following:

D. Clausse, A. Drelich and B. Fouconnier (2011). Mass Transfers Within Emulsions Studied by Differential Scanning Calorimetry (DSC) - Application to Composition Ripening and Solid Ripening, Mass Transfer Advanced Aspects, Dr. Hironori Nakajima (Ed.), ISBN: 978-953-307-636-2, InTech, Available from: http://www.intechopen.com/books/mass-transfer-advanced-aspects/mass-transfers-within-emulsions-studiedby-differential-scanning-calorimetry-dsc-application-to-comp

\section{INTECH}

open science | open minds

\author{
InTech Europe \\ University Campus STeP Ri \\ Slavka Krautzeka 83/A \\ 51000 Rijeka, Croatia \\ Phone: +385 (51) 770447 \\ Fax: +385 (51) 686166 \\ www.intechopen.com
}

\author{
InTech China \\ Unit 405, Office Block, Hotel Equatorial Shanghai \\ No.65, Yan An Road (West), Shanghai, 200040, China \\ 中国上海市延安西路65号上海国际贵都大饭店办公楼 405 单元 \\ Phone: +86-21-62489820 \\ Fax: $+86-21-62489821$
}


(C) 2011 The Author(s). Licensee IntechOpen. This is an open access article distributed under the terms of the Creative Commons Attribution 3.0 License, which permits unrestricted use, distribution, and reproduction in any medium, provided the original work is properly cited. 